\title{
Albumin-encapsulated Nanoparticles of Naproxen Platinum(IV) Complexes with Inflammation Inhibitory Competence Displaying Effective Antitumor Activities in vitro and in vivo
}

\author{
Linming $\mathrm{Li}^{1, *}$ \\ Yan Chen ${ }^{1} * *$ \\ Qingpeng Wang \\ Zuojie $\mathrm{Li}^{1}$ \\ Zhifang Liu' \\ Xuewen Hua' \\ Jun Han (D) \\ Chunxiao Chang ${ }^{2}$ \\ Zhengping Wang ${ }^{1,3}$ \\ Dacheng $\mathrm{Li}^{1,4}$
}

'Institute of Biopharmaceutical Research, Liaocheng University, Liaocheng, 252059, People's Republic of China; ${ }^{2}$ Shandong Cancer Hospital and Institute, Shandong First Medical University and Shandong Academy of Medical Sciences, Jinan, 250022, People's Republic of China; ${ }^{3}$ Liaocheng High-Tech Biotechnology Co., Ltd, Liaocheng, 252059, People's Republic of China; ${ }^{4}$ Shandong Provincial Key Laboratory of Chemical Energy Storage and Novel Cell Technology, Liaocheng University, Liaocheng, 252059, People's Republic of China

*These authors contributed equally to this work

Correspondence: Qingpeng Wang

Institute of Biopharmaceutical Research,

Liaocheng University, Liaocheng, 252059,

People's Republic of China

Tel/Fax +86 6358239773

Email lywqp@।26.com

Chunxiao Chang

Shandong Cancer Hospital and Institute,

Shandong First Medical University and

Shandong Academy of Medical Sciences,

Jinan, 250022, People's Republic of China

Email changcx-III@I63.com
Background: Platinum(IV) complexes with inflammation inhibitory properties are much favored in improving antitumor activities. Nanodrug-delivery system as a preferable measure for antitumor therapy are widely explored in platinum(IV) drug delivery.

Purpose: The aim for this study was to develop novel bovine serum albumin (BSA) nanoparticles (NPs) based on naproxen platinum(IV) complexes to display a synergistic antitumor mechanism targeting cyclooxygenase-2 (COX-2), metalloproteinase-9 (MMP-9) and inducible nitric oxide synthase (iNOS).

Methods: Herein, we reported the preparation of two BSA NPs of naproxen platinum(IV) complexes, and their antitumor activities were investigated in vitro and in vivo.

Results: Both NPs possessed relatively uniform size and good stability for 30 days in aqueous solution. They exhibited prominent antitumor activities in vitro, and showed great potential in reversing drug resistance. Furthermore, these two NPs played superior tumor growth suppression in vivo in contrast to the free compounds, which were comparable to that of cisplatin and oxaliplatin, but induced lower toxic influences than platinum(II) drugs especially to spleen and liver. Moreover, the naproxen platinum(IV) NPs could decrease tumor inflammation targeting COX-2, MMP-9 and iNOs, and decreasing NO production, which would be in favor of enhancing the antitumor competence, and reducing toxicity.

Conclusion: Taken together, BSA NPs of naproxen platinum(IV) complexes demonstrated a powerful antitumor efficacy in vitro and in vivo. The platinum(IV) NPs with inflammation inhibitory competence targeting multiple enzymes reported in this work afford a new strategy for the development of antitumor therapy to overcome drawbacks of clinical platinum(II) drugs.

Keywords: bovine serum albumin nanoparticles, cyclooxygenase-2, metalloproteinases-9, inducible nitric oxide synthase, synergistic antitumor efficacy

\section{Introduction}

Cancer is a major public problem worldwide and seriously threats human health and life. ${ }^{1,2}$ Chemotherapy as a systemic treatment is widely applied in the treatment of various tumors for its superior effectiveness, especially to the tumors at advanced stages. Nanodrug-delivery system (nano-DDS) provides a new effective tool for chemotherapy in clinics. ${ }^{3}$ Nanodelivery of various chemotherapeutic drugs has received tremendous attention in the past decades owing to their superiority in 


\section{Graphical Abstract}

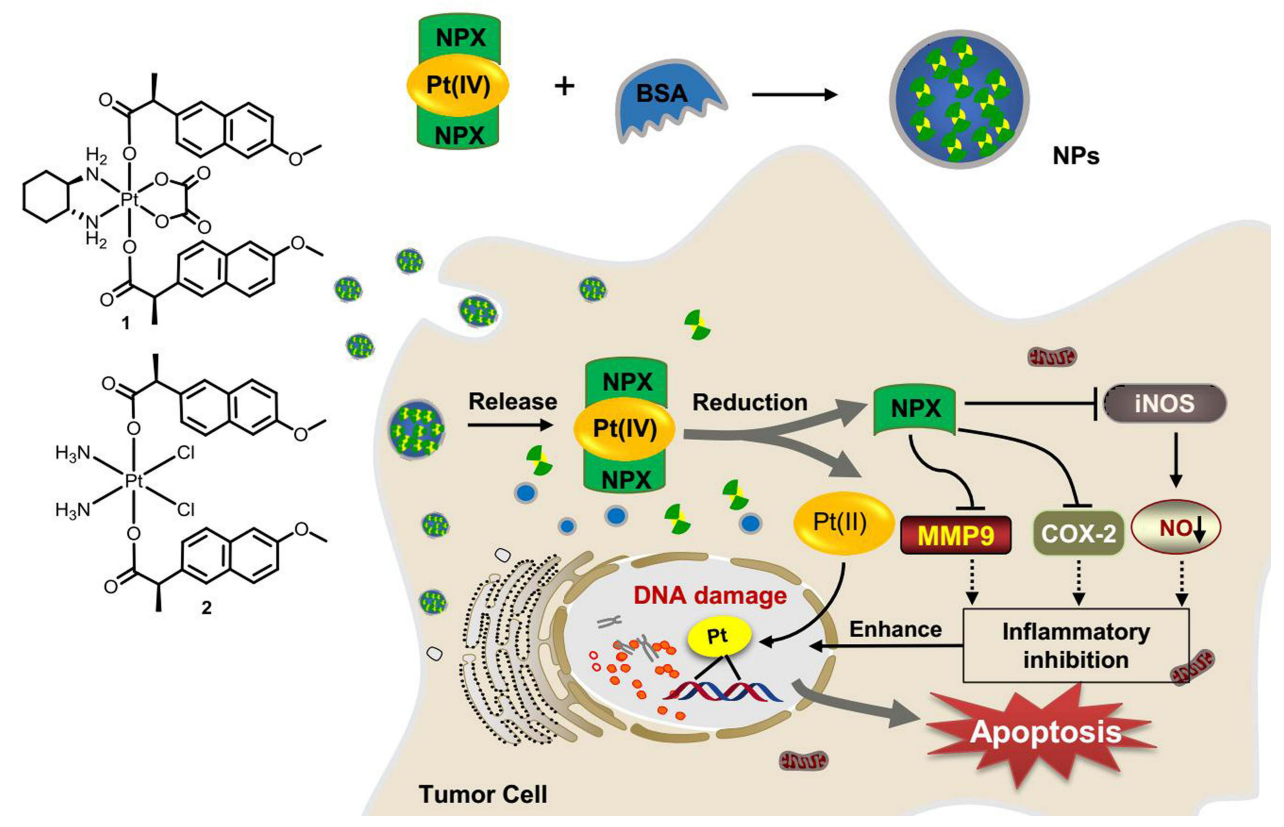

improving drug solubility, increasing accumulation in tumors, reducing side effects and prolonging blood circulation time. Moreover, taking advantage of the enhanced permeability and retention (EPR) effect in tumor tissues, nanoparticles (NPs) facilitate drug targeting to tumor tissues, and further influence their activities and toxic properties. ${ }^{4,5}$ The investigation on nano-DDS of chemotherapeutics has been a hot topic in cancer treatments.

Platinum drugs play a pivotal role in cancer treatment in clinics. Especially cisplatin, carboplatin, and oxaliplatin are highly effective in cancer chemotherapy. 6,7 The injection of platinum(II) drugs usually involves a high peak of drug level above the maximum tolerable concentration (MTC) in the plasma, rapid elimination and low bioavailability, which causes severe side effects, drug resistance, etc, and further hinders their scope of use. Nano-DDS exhibits unique advantages in drug controlled release and is extensively exploited for platinum drug delivery. ${ }^{8}$ Nevertheless, low lipophilicity and poor stability of traditional platinum(II) drugs limit the formation of the NPs especially when injected into the bloodstream. ${ }^{9,10}$ Platinum(IV) complexes as prodrugs of platinum(II) drugs with $d^{6}$ octahedral geometry show rather enhanced lipophilicity and stability. ${ }^{11,12}$ Large amounts of platinum(IV) based nano-DDS have been developed and exhibited significant superiority over free platinum drugs.
Serum albumin nanocarriers represent one of the most promising carriers recently generated because of their good biocompatibility, low immunogenicity, biodegradability, and favorable toxicological profiles. ${ }^{13,14}$ Moreover, albumin nanocarriers are potent in improving the stability of sensitive therapeutic cargos and possess much potential in targeting tumor cells. ${ }^{15}$ Especially, the market of serum albumin nanomedicine Abraxane ${ }^{\circledR}$ (paclitaxel) lightens the enthusiasm of researchers on serum albumin nanoparticles. ${ }^{16}$ Bovine serum albumin (BSA) with high sequence homology $(76.52 \%)$ to human serum albumin (HSA), wide source and low cost has been widely investigated. ${ }^{17-20}$ Whereas, the serum albumin NPs loaded platinum(IV) drugs were seldom investigated. Moreover, it has been proven that the conjunction of platinum(IV) drugs with albumin could significantly decrease the reduction rate and enhance stability of drugs in whole blood. ${ }^{21}$ Thereby, it is of great interest for us to design a series of BSA nanoparticle-loaded platinum(IV) complexes and further investigate their antitumor properties.

Inflammation is an important hallmark in cancer progression associated with the occurrence, development and metastasis of malignancy. ${ }^{22,23}$ Inflammation inhibition during the cancer treatment plays essential roles in improving efficacy of chemotherapeutics. ${ }^{24,25}$ Several non-steroid anti-inflammatory drugs (NSAIDs) like aspirin, ibuprofen, 
indomethacin, and flurbiprofen, which display dramatic anti-inflammatory properties mainly targeting cyclooxygenases (COXs), have been incorporated with the platinum(IV) system to form a series of promising complexes. $^{26-38}$ The mechanism detection discloses that these complexes display prominent inflammation inhibitory properties besides causing serious DNA damage. Our previous work reported a series of mono-naproxen platinum(IV) complexes with prominent antitumor activities, which showed great potential in inhibiting tumor migration by synergistic inhibition of COX-2 and matrix metalloproteinases (MMPs). ${ }^{39}$ More recently, Guo and Wang's group reported the efficient antitumor performance of dual naproxen platinum(IV) complex $2 .^{40}$ It targeted COX-2 and PD-L1 via multiple pathways to significantly inhibit the immune escape of tumor cells and finally improve antitumor efficacy. Thereby, naproxen platinum(IV) complex represents a promising scaffold for further development of novel platinum drugs.

In view of the potent activities of NSAID derived platinum(IV) complexes and the advantages of nanoDDS, nanoparticles of NSAID platinum(IV) would be effective to facilitate cellular uptake and improve apoptosis-inducing ability. ${ }^{32}$ However, nano-DDS based on biocompatible BSA loading such platinum(IV) complexes has not been reported. Inspired by these observations and as a continuation of our interest in developing new platinum antitumor drugs, ${ }^{41-43}$ two dual naproxen platinum(IV) complexes $\mathbf{1}$ and $\mathbf{2}$ with oxaliplatin and cisplatin cores were prepared (Figure 1). Then, BSA nanoparticles 1-NPs and 2-NPs loaded with dual naproxen platinum(IV) complexes were designed, prepared, and characterized. Their antitumor activities and toxic properties were evaluated in vitro and in vivo, and their likely antitumor mechanisms were also detected.

\section{Materials and Methods \\ Chemistry \\ General}

All reactions were carried out under an atmosphere of nitrogen in flame-dried glassware with magnetic stirring unless otherwise indicated. Cisplatin and oxaliplatin were purchased from Boyuan Chemical Co. Ltd (Jinan, China). Other reagents were obtained from Sigma, Aladdin, Innochem, and J\&K Scientific Ltd. ${ }^{1} \mathrm{H}$ NMR and ${ }^{13} \mathrm{C}$ NMR spectra were recorded on a Bruker $(500 \mathrm{MHz}$ and $125 \mathrm{MHz}$ ). All NMR chemical shifts were referenced to residual solvent peaks or TMS as an internal standard. All coupling constants $J$ were quoted in Hz. Mass spectra (MS) were obtained on a Shimadzu LC-MS/MS 8040 mass spectrometer with ESI ionization. The particle size (Z-average), polydispersity index and zeta potential were detected by dynamic light scattering (DLS, Zetasizer Nano ZSP, Malvern, UK). Transmission electron microscope (TEM) was recorded on JEM-2100 (JEOL, Japan). The BSA was purchased from J\&K. Genomic DNA minipreparation kit, was purchased from Beyotime, China. UVvis spectra were measured on a Scinco S-3100 UV-vis spectrophotometer. The fluorescence spectra were recorded on a Hitachi F-7000. The cells were purchased from Procell Life Science \& Technology Co., Ltd (China).

\section{Synthetic Procedures}

The synthetic procedures for oxoplatin 01-02 were supplied in the supporting information according to procedures reported in the literature. ${ }^{42,44}$

\section{Preparation of Compound I}

Complex 1 was prepared as reported in our previous work. $^{39}$ A solution of naproxen $(134 \mathrm{mg}, 0.58 \mathrm{mmol}$ ) and $N, N, N^{\prime}, N^{\prime}$-tetramethyl-O-(benzotriazol-1-yl)uranium tetrafluoroborate (TBTU) $(187 \mathrm{mg}, 0.58 \mathrm{mmol})$ in dry DMF $5 \mathrm{~mL}$ was stirred at room temperature for $10 \mathrm{~min}$ after injection of $N, N, N$-triethylamine (TEA) $(80 \mu \mathrm{L}, 0.58$ $\mathrm{mmol}$ ). Subsequently, oxoplatin 01 (86 mg, $0.20 \mathrm{mmol}$ ) was added, and the reaction mixture was stirred vigorously at $50^{\circ} \mathrm{C}$ for $48 \mathrm{~h}$ in the dark. After the reaction completed, the solvent was evaporated and the residue was purified by silica gel column chromatography using dichloromethanemethanol (80: 1, v/v). Complex 1 was obtained as white solid (54.8 mg, 32\%), with $97.9 \%$ purity as determined by HPLC (methanol- $\mathrm{H}_{2} \mathrm{O}, 70 \%$ ).

${ }^{1} \mathrm{H}$ NMR $\left(500 \mathrm{MHz}, \mathrm{DMSO}-d_{6}\right) \delta 7.80-7.65(\mathrm{~m}, 6 \mathrm{H})$, 7.39-7.34 (m, 2H), 7.27 (s, 2H), 7.15-7.10 (m, 2H), 3.92$3.82(\mathrm{~m}, 8 \mathrm{H}), 2.26-2.03(\mathrm{~m}, 2 \mathrm{H}), 1.98-1.78(\mathrm{~m}, 2 \mathrm{H})$, $1.46-1.36(\mathrm{~m}, 6 \mathrm{H}), 1.26-1.20(\mathrm{~m}, 2 \mathrm{H}), 1.16-1.07(\mathrm{~m}$, 2H), 0.77-0.49 (m, 2H). 13C NMR (126 MHz, DMSO$\left.d_{6}\right) \delta 182.2,163.6,157.5,137.3,133.6,129.5,128.8$, 127.1, 127.0, 125.8, 119.0, 106.1, 61.3, 55.6, 46.9, 31.2, 23.5, 19.6. ESI-MS: calcd for $[\mathrm{M}+\mathrm{H}]+$ : $857(\mathrm{M}=$ $\mathrm{C}_{36} \mathrm{H}_{40} \mathrm{~N}_{2} \mathrm{O}_{10} \mathrm{Pt}$ ), found: 857 . $^{39}$

Preparation of Compound 2

A solution of naproxen (134 $\mathrm{mg}, 0.58 \mathrm{mmol})$ and TBTU (187 $\mathrm{mg}, 0.58 \mathrm{mmol}$ ) in dry DMF $5 \mathrm{~mL}$ was stirred at 


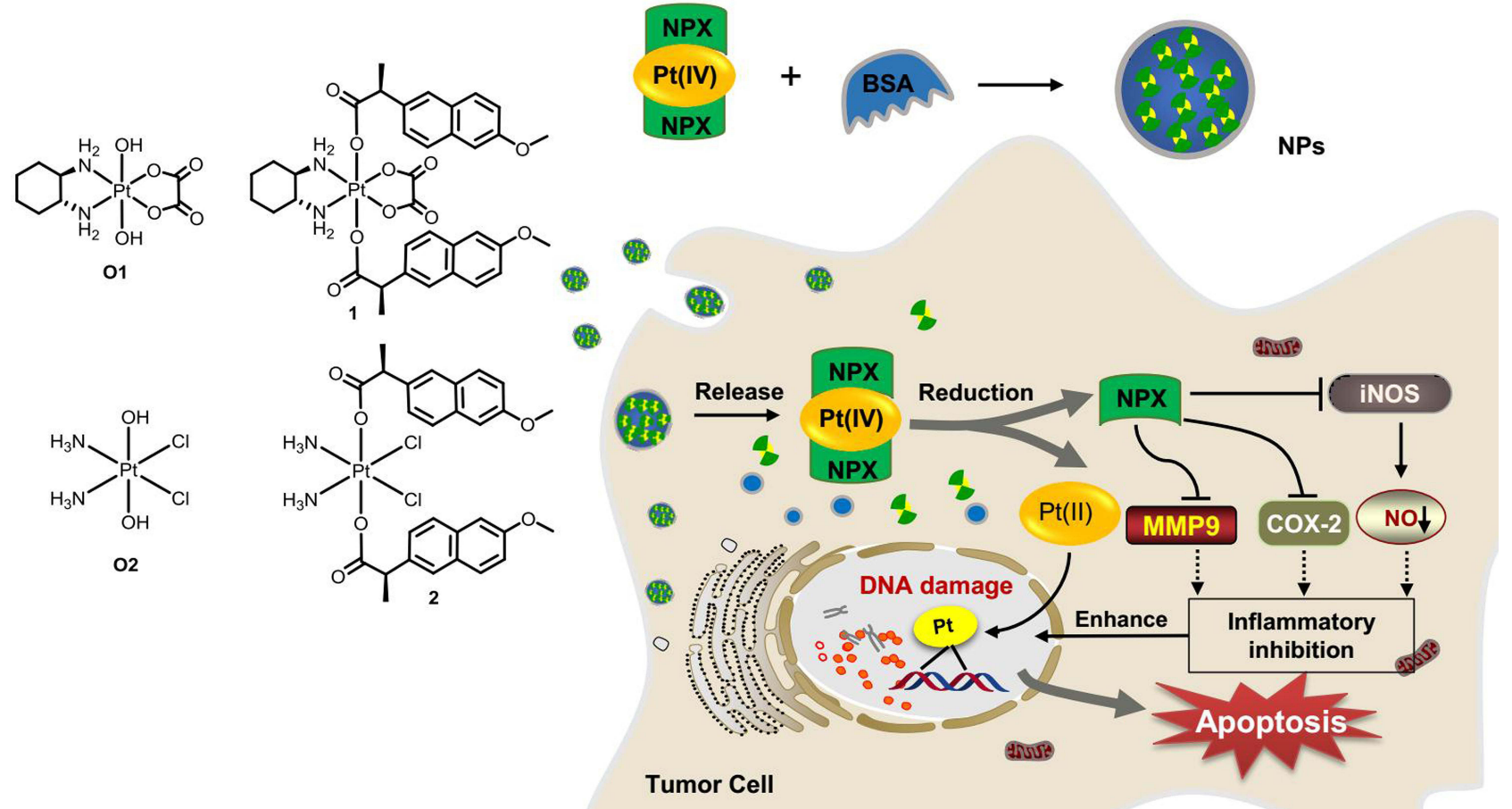

Figure I Structure of oxoplatins $\mathbf{O} \mathbf{I}$ and $\mathbf{O 2}$, dual naproxen platinum(IV) complexes I and 2, the preparation of nanoparticles I-NPs and 2-NPs, and their likely antitumor mechanism.

Abbreviations: NPs, nanoparticles; BSA, bovine serum albumin; COX-2, cyclooxygenase-2; MMP-9, metalloproteinase-9; iNOS, inducible nitric oxide synthase.

room temperature for 10 min after injection of TEA $(80$ $\mu \mathrm{L}, 0.58 \mathrm{mmol})$. Subsequently, oxoplatin $\mathbf{O 2}(67 \mathrm{mg}$, $0.20 \mathrm{mmol}$ ) was added, and the reaction mixture was stirred vigorously at $50^{\circ} \mathrm{C}$ for $48 \mathrm{~h}$ in dark. After the reaction completed, the solvent was evaporated and the residue was purified by silica gel column chromatography using dichloromethane-methanol (70:1, v/v). Complex 2 was obtained as white solid (36.4 mg, 24\%). $98.1 \%$ purity determined by HPLC (methanol- $\mathrm{H}_{2} \mathrm{O}, 70 \%$ ).

${ }^{1} \mathrm{H}$ NMR $\left(500 \mathrm{MHz}, \mathrm{DMSO}-d_{6}\right) \delta 7.82-7.68(\mathrm{~m}, 6 \mathrm{H})$, $7.48(\mathrm{~d}, J=8.4 \mathrm{~Hz}, 2 \mathrm{H}), 7.27$ (s, 2H), 7.13 (dd, $J=8.9,1.9$ $\mathrm{Hz}, 2 \mathrm{H}), 6.55$ (s, 6H), $3.86(\mathrm{~s}, 6 \mathrm{H}), 3.07$ (d, $J=7.0 \mathrm{~Hz}$, 2H), $1.41(\mathrm{~d}, J=7.1 \mathrm{~Hz}, 6 \mathrm{H}) .{ }^{13} \mathrm{C} \mathrm{NMR}(126 \mathrm{MHz}$, DMSO- $\left.d_{6}\right) \delta 182.47,157.40,137.84,133.51,129.55$, $128.83,127.47,126.82,125.97,118.83,106.14,55.61$, 46.88, 46.22, 20.29. ESI-MS: Calcd. for $[\mathrm{M}+\mathrm{H}]^{+}: 759$ ( $\mathrm{M}=\mathrm{C}_{28} \mathrm{H}_{32} \mathrm{Cl}_{2} \mathrm{~N}_{2} \mathrm{O}_{6} \mathrm{Pt}$ ), found: 759 .

\section{Preparation of Nanoparticles I-NPs and 2-NPs}

Briefly, free compound 1 or 2 (5 mg, 1.0 eq.) was dissolved in $1.5 \mathrm{~mL}$ ethanol containing 5\% dichloromethane under continuous ultrasonication. The organic solution was added dropwise into $15 \mathrm{~mL}$ deionized water with BSA (complex 1 or 2/BSA; 2.0 eq./1.0 eq.,
3.0 eq./1.0 eq., 5.0 eq./1.0 eq. and 7.5 eq./1.0 eq.), and the mixture was stirred for $20 \mathrm{~min}$ vigorously at room temperature. Then, the organic solvent was evaporated under vacuum to about $12 \mathrm{~mL}$. The obtained NPs were then homogenized by a D-3L homogenizer (PhD, USA) at optimal homogenization conditions of $100 \mathrm{MPa}$ for $15 \mathrm{~min}$ to reduce the particle size. Then, deionized water was supplied, and solution of nanoparticles $15 \mathrm{~mL}$ was obtained.

\section{Characterization of NPs}

The particle size (Z-average), polydispersity index and zeta potential of NPs were detected by dynamic light scattering (DLS, Zetasizer Nano ZSP, Malvern, UK) with an integrated $4 \mathrm{mV}$ He-Ne laser $(\lambda=633 \mathrm{~nm})$ and the backscattering detection (scattering angle $\theta=173^{\circ}$ ) at set temperature. Experiments were performed in triplicate.

The morphology of NPs was analyzed by transmission electron microscope (TEM, JEM-2100, JEOL, Japan). One drop of NP (100 $\mu \mathrm{g} / \mathrm{mL}$ of free complex) was placed on a carbon-coated copper grid and stained with uranyl acetate $(2 \%, \mathrm{w} / \mathrm{v})$. The TEM observations were performed at an accelerating voltage of $80 \mathrm{kV}$. 


\section{Biological Evaluation}

In vitro Cellular Cytotoxicity Assays

The naproxen platinum(IV) nanoparticles 1-NPs, 2-NPs and free compounds $\mathbf{1 , 2}$ were evaluated for antitumor activities against four tumor cell lines including human lung cancer (A549), human ovarian cancer (SKOV-3), murine colon cancer (CT-26) and a cisplatin-resistant cell line A549R, and a human normal liver cell line LO-2 using a 3-(4,5-dimethylthiazol-2-yl)-2,5-diphenyltetrazolium bromide (MTT) assay with cisplatin, oxaliplatin, and naproxen as reference drugs. ${ }^{45}$ A BSA nanoparticle without drugs was prepared and tested as a vehicle. The cells were maintained in RPMI1640 medium containing $10 \%$ FBS in a humidified atmosphere containing $5 \% \mathrm{CO}_{2}$ at $37^{\circ} \mathrm{C}$. The $\mathrm{A} 549 \mathrm{R}$ was maintained with $2 \mu \mathrm{g} / \mathrm{mL}$ cisplatin. Phosphate buffered saline (PBS) contained $137 \mathrm{mM} \mathrm{NaCl}, 2.7 \mathrm{mM} \mathrm{KCl}, 10 \mathrm{mM} \mathrm{Na}_{2} \mathrm{HPO}_{4}$ and $2 \mathrm{mM} \mathrm{KH}_{2} \mathrm{PO}_{4}$ (pH 7.4). MTT solution at concentration of $5 \mathrm{mg} \cdot \mathrm{mL}^{-1}$ for MTT assays was prepared before use.

Cells were seeded in 96-well plates at 5000 cells per well in $100 \mu \mathrm{L}$ of complete medium, and incubated for $24 \mathrm{~h}$ in a $5 \% \mathrm{CO}_{2}$ atmosphere at $37^{\circ} \mathrm{C}$. Then freshly prepared culture medium $100 \mu \mathrm{L}$ containing drugs at different concentrations were added. The cells were further incubated for another $48 \mathrm{~h}$ or $72 \mathrm{~h}$. After that, freshly prepared MTT solution $\left(5 \mathrm{mg} \cdot \mathrm{mL}^{-1}\right) 20 \mu \mathrm{L}$ was added. The resultant mixtures were incubated for $4 \mathrm{~h}$ to allow viable cells to reduce the yellow tetrazolium salt into dark blue formazan crystals. After removal of the medium, formazan was dissolved in DMSO $(150 \mu \mathrm{L})$ and quantified by a microplate reader $(570 \mathrm{~nm})$. The $\mathrm{IC}_{50}$ values were calculated using GraphPad Prism 6 based on three parallel experiments.

\section{In vivo Antitumor Assay}

Male BALB/c mice (18-20 g) were purchased from the Laboratory Animal Center, Shandong University (Shandong, China). This study was performed in strict accordance with the NIH guidelines for the care and use of laboratory animals (NIH Publications No. 8023, revised 1978), and was approved by the Institute Animal Ethics Committee of Liaocheng University (Liaocheng, China).

Murine CT-26 cells $\left(5 \times 10^{5}\right)$ suspended in PBS were injected subcutaneously into the right flank of BALB/c mice and therapy was started when tumor nodules were palpable (day 6). The mice were divided into seven groups randomly, saline; cisplatin (2 mg Pt/kg, i.v.); oxaliplatin
(4 mg Pt/kg, i.v.); compound 1 (4 mg Pt/kg, i.p.), 1-NPs (4 mg Pt/kg, i.v.); compound 2 (2 mg Pt $/ \mathrm{kg}$, i.p.), 2-NPs ( $2 \mathrm{mg} \mathrm{Pt} / \mathrm{kg}$, i.v.). Freshly prepared solutions of drugs were administered four times, on days $6,9,12$, and 14 posttumor inoculation. Tumor volume $(V)$ was determined as $V=L \times W^{2} / 2$, where the length $(L)$ and width $(W)$ were measured. At day 15, $24 \mathrm{~h}$ after the last drug application, the mice were euthanized. The tumors were excised and weighed. The blood and tissues including liver, heart, spleen, lung, and kidney were collected. Then, tissues were formalin-fixed in $4 \%$ formaldehyde overnight, paraffin-embedded, and cut with a microtome ( $5 \mu \mathrm{m}$ sections) for hematoxylin and eosin (H\&E) staining and immunohistochemical detection.

\section{Determination of NO Production}

The cells RAW $264.7\left(1 \times 10^{6}\right.$ cells/well $)$ in $100 \mu \mathrm{L}$ media were preincubated in 96-well plates for $24 \mathrm{~h}$. Then the media was removed. Fresh media $100 \mu \mathrm{L}$ containing lipopolysaccharide (LPS) $(1 \mu \mathrm{g} / \mathrm{mL})$ and drug at different concentrations were added and the cells were further incubated for $24 \mathrm{~h}$. Then, the growth medium $75 \mu \mathrm{L}$ was mixed with the same volume of Griess reagent for $5 \mathrm{~min}$ and absorbance was measured at $570 \mathrm{~nm}$. The accumulation amount of nitrite was determined as an index of NO. Three replicates were performed for all the treatments.

\section{AST, ALT, BUN and CRE Detection}

The blood of mice was collected in Eppendorf tubes and centrifuged at $1500 \mathrm{~g}$ for $15 \mathrm{~min}$ to collect serum samples. Then the AST, ALT, BUN and CRE were detected using enzyme-linked immunosorbent assay kits according to the manufacturer's instructions: serum aspartate aminotransferase (AST ELISA kit, Nanjing Jiancheng Bioengineering Institute, China), alanine aminotransferase (ALT ELISA kit, Nanjing Jiancheng Bioengineering Institute, China), blood urea nitrogen (BUN ELISA kit, Nanjing Jiancheng Bioengineering Institute, China) and creatinine (CRE ELISA kit, Nanjing Jiancheng Bioengineering Institute, China). The OD values were recorded on an automatic microplate reader (Tecan Spark).

\section{COX-2 Inhibition}

The COX inhibitory experiment was carried out using a cyclooxygenase 2 inhibitor screening kit (Beyotime, China) according to the manufacturer's protocol. The rhCOX-2 was applied in the experiments. The inhibitions of compounds 1 and 2 at different concentrations (5, 20 $\mu \mathrm{M})$ and naproxen at corresponding concentrations (10, 40 
$\mu \mathrm{M})$ to COX-2 were tested. Then the reduced systems of complexes $\mathbf{1}$ and $\mathbf{2}$ with ascorbic acid (AsA) (Compd.AsA) were prepared by incubation of compound $\mathbf{1} / \mathbf{2}$ solution under treatment of AsA $(1 \mathrm{mM})$ for $48 \mathrm{~h}$ to allow the platinum(IV) to totally convert to platinum(II) complexes with release of two equivalent of naproxen. The compound 1-AsA and compound 2-AsA were also tested at concentrations of 5 and $20 \mu \mathrm{M}$. Then, cisplatin and oxaliplatin at $20 \mu \mathrm{M}$ were also evaluated. The sample with no rhCOX-2 inhibitor was evaluated as blank, and celecoxib was used at the suggested concentration in the protocol $(100 \mathrm{nM})$ as positive reference sample.

\section{Immunohistochemical Detection}

Tumor tissues of 1-NPs, 1, oxaliplatin and saline treated groups were stained using MMP-9 and iNOS staining assays according to the standard procedure. Immunohistochemistry was performed on formalinfixed, paraffin-embedded organism sections. Following deparaffinization and hydration, sections were immersed into citrate buffer, boiled in a microwave for antigen repair and blocked in 10\% normal goat serum (Sigma, USA) for $60 \mathrm{~min}$. Then, sections were incubated at $4^{\circ} \mathrm{C}$ with primary antibody MMP-9 (Servicebio, China; DILution ratio, 1:100) or iNOS (Proteintech; DILution ratio, 1:800) overnight. Subsequently, sections were washed in PBS and incubated with goat anti-mouse IgEHRP secondary antibody (Servicebio, China; DILution ratio, 1:200) for $50 \mathrm{~min}$ at room temperature. After washed with PBS, the sections were visualized with 3,3'-diaminobenzidine (DAB) (Servicebio, China), and counterstained using hematoxylin. The MMP-9 and iNOS index was calculated as the mean optical density (percent) by choosing five random fields with an optical microscope.

\section{Accumulation of Platinum in Whole Cells and DNA}

The CT-26 cells were seeded in 6-well cell culture plate and incubated for $12 \mathrm{~h}$ at $37^{\circ} \mathrm{C}$. Then the cells were treated with platinum compounds $(100 \mu \mathrm{M})$ including nanoparticles 1-NPs, 2-NPs, complexes 1, 2 and reference drugs cisplatin, oxaliplatin for $10 \mathrm{~h}$ in incubator. After that, all the cells were harvested, collected and washed for three times with PBS. Approximately one million cells were mineralized with $70 \%$ $\mathrm{HNO}_{3}(\mathrm{LC})$, and the platinum in cells was determined with ICP-MS. Results were presented as the mean of three determinations for each data point. To test the DNA platination of the tumor cells, the DNA of approximately one million cells was isolated with a Genomic DNA Mini-Preparation Kit (Beyotime, China). Then the DNA was mineralized with $70 \% \mathrm{HNO}_{3}$ and measured by ICP-MS.

\section{Platinum in Tumor, Liver and Kidney}

Tissues including tumor, liver and kidney from nanoparticles 1-NPs, 2-NPs, free compounds 1, 2, reference drugs cisplatin and oxaliplatin treated groups were collected and mineralized with $70 \% \mathrm{HNO}_{3}$ (LC). The platinum in tissues was determined with ICP-MS.

\section{Fluorescence and UV-vis Spectra Assays for BSA Interaction}

The fluorescence spectra were recorded on a Hitachi F-7000 spectrofluorometer using a quartz cell of $1.00 \mathrm{~cm}$. The slits of both excitation and emission were $5.0 \mathrm{~nm}$. The quenching spectra of BSA were recorded by the gradually addition of compound $\mathbf{1} / \mathbf{2}(0.0,8.0,14.0$, $20.0 \mu \mathrm{M})$ to BSA solution $(4.0 \mu \mathrm{M})$ in buffer $(10 \mathrm{mM}$ Tris$\mathrm{HCl} / 10 \mathrm{mM} \mathrm{NaCl}, \mathrm{pH}$ 7.4). The well-mixed solutions were holding for $15 \mathrm{~min}$ for equilibrium and tested under excitation of $298 \mathrm{~nm}$ at a scan rate of $300 \mathrm{~nm} \cdot \mathrm{min}^{-1}$ under excitation of $280 \mathrm{~nm}$. The fluorescence spectra of free complexes $(20.0 \mu \mathrm{M})$ were also detected.

Then, the UV-vis spectra were also employed to testify the BSA interaction of compounds $\mathbf{1}$ and $\mathbf{2}$. The solution of BSA $(10 \mu \mathrm{M})$ was recorded as line a. The solution of BSACompound $(1: 1)(10 \mu \mathrm{M})$ was recorded as line $b$. The solution of compound $(10 \mu \mathrm{M})$ was recorded as line c. Line $\mathrm{d}$ was obtained by the subtraction of line $\mathrm{b}$ and line $\mathrm{c}$.

\section{Results and Discussion}

\section{Chemistry}

The Synthesis of Naproxen Platinum(IV) Complexes Naproxen platinum(IV) complexes $\mathbf{1}$ and $\mathbf{2}$ were prepared by the condensation of naproxen with oxoplatins $\mathbf{O 1}$ and $\mathbf{O 2}$ in the presence of TBTU and TEA (Figure S1). Oxoplatins $\mathrm{O} 1$ and $\mathrm{O} 2$ were obtained by the oxidation of cisplatin, oxaliplatin with hydrogen peroxide as reported in our previous work. ${ }^{46,47}$

\section{The Particle Size, Zeta Potential and Morphology}

The BSA nanoparticles of complexes $\mathbf{1}$ and $\mathbf{2}$ were prepared for four drug/BSA ratios (complex 1 or $2 / \mathrm{BSA} ; 2.0$ eq./1.0 eq., 3.0 eq./1.0 eq., 5.0 eq./1.0 eq. and 7.5 eq./1.0 eq.) as shown in Tables S1 and S2. The results revealed that drug/ BSA ratio of 3.5:1 is suitable for preparing the 1-NPs due to 

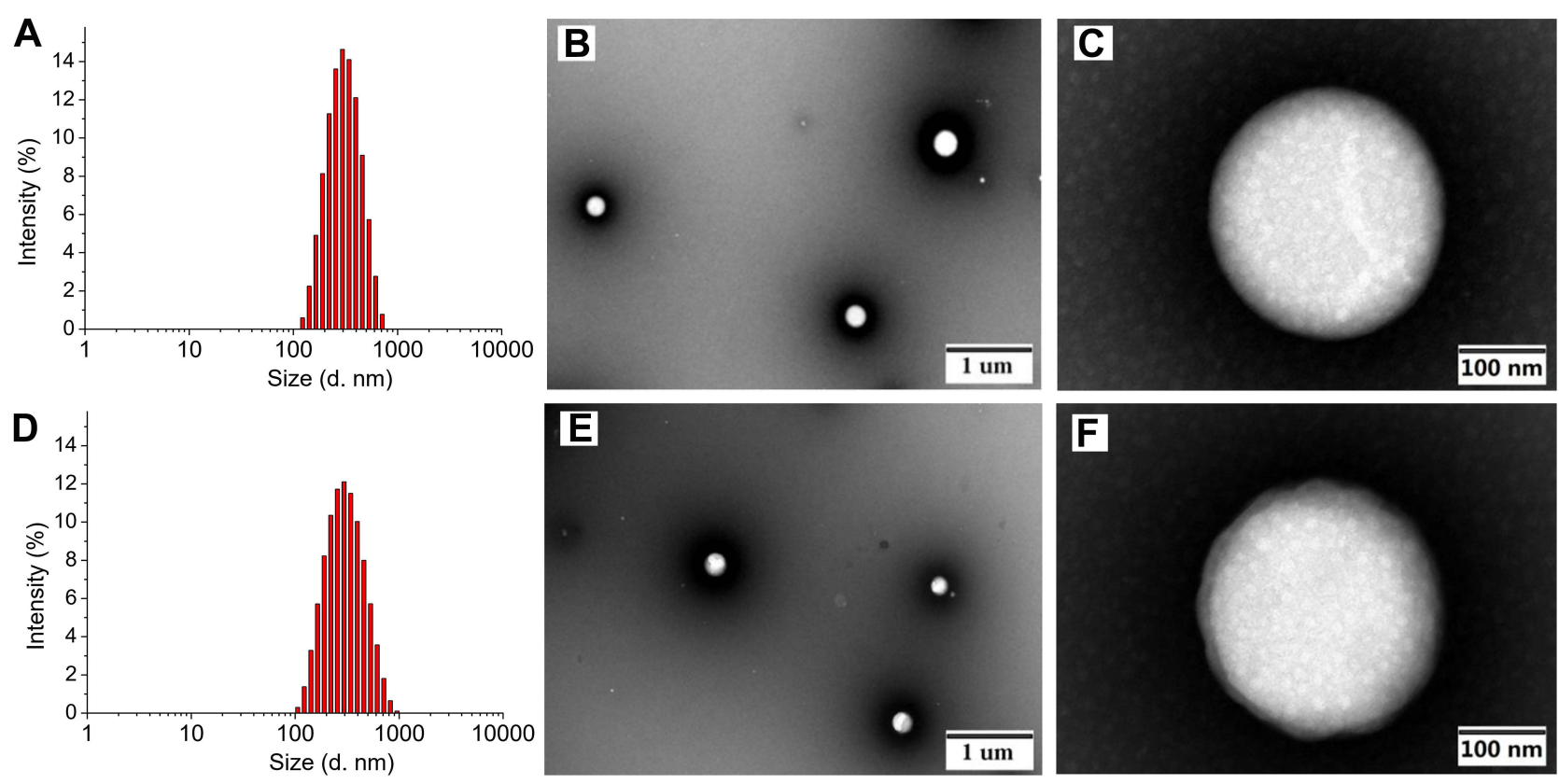

Figure 2 Mean hydrodynamic diameter determined by DLS, and TEM images of I-NPs (A-C) and 2-NPs (D-F). Abbreviations: DLS, dynamic light scattering; TEM, transmission electron microscope; NPs, nanoparticles.

the minimum size $(280.2 \pm 6.5 \mathrm{~nm})$, narrow distribution $(\mathrm{PDI}=0.32 \pm 0.03)$ and high zeta potential $(-29.5 \pm 0.3 \mathrm{mV})$. Meanwhile, drug/BSA ratio of 5.0:1 is suitable for preparing the 2-NPs, which affords particles with minimum size of $273.1 \pm 1.5 \mathrm{~nm}$, low PDI of $0.30 \pm 0.02$, and high zeta potential of $-22.8 \pm 0.8 \mathrm{mV}$ (Figure 2). It was proven that the NPs with negative surface charge would show preferential uptake at the tumor site with higher cationic charge density in comparison with normal organs. ${ }^{48,49}$ Thereby, the negative zeta potential of the NPs indicates that 1-NPs and 2-NPs keep stable in aqueous environment, and these facts might be a factor accounting for the high accumulation of nanoparticles in tumor cells and tissues as depicted by cellular uptake results (see, tumor target properties section). Subsequently, the morphology of 1-NPs and 2-NPs were observed by TEM. Both particles are mostly uniform spheres in shape without sign of agglomeration with size of $275 \mathrm{~nm}$ and 283 $\mathrm{nm}$ respectively. These results coincide with the size analyzed by DLS.

To illustrate the assembled mechanism of 1-NPs and 2-NPs, the interaction of complexes $\mathbf{1}$ and $\mathbf{2}$ with BSA were investigated by fluorescence and UV-vis absorption spectroscopies. The fluorescence spectroscopy is widely applied in the exploration of structural and conformational changes of proteins. The fluorescence spectra in Figure S2 demonstrate that the emission fluorescence of BSA at $340 \mathrm{~nm}$ is quenched with the addition of platinum(IV) complexes $\mathbf{1}$ or $\mathbf{2}$. These facts indicate that complexes $\mathbf{1}$ and $\mathbf{2}$ could combine with BSA noncovalently. Then, UV-vis spectra of BSA in the absence and presence of compounds 1 and 2 (Figure S3) were measured to determine the binding mechanism. The differential absorption spectra (curve d) between compound 1/2-BSA complex (curve a) and platinum(IV) complex 1/2 (curve c) are apparently different from the spectra of BSA (curve b) at equivalent concentrations. Conclusively, the binding of platinum(IV) complexes $\mathbf{1}$ and $\mathbf{2}$ with BSA is a static quenching process due to the complex formation.

\section{Stability Studies}

The long-term storage stability studies of 1-NPs and 2-NPs were performed at $4^{\circ} \mathrm{C}$ with size measurement by DLS. The nanoparticles 1-NPs and 2-NPs exhibit no dramatic change of size, PDI and zeta potential during 30 days storage at $4^{\circ} \mathrm{C}$, $\mathrm{pH}=7.4$. The results in Figure 3 (Table S3) manifested that the mean hydrodynamic diameter of 1-NPs was $266.0 \pm 16.7$ $\mathrm{nm}$ with a narrow distribution $(\mathrm{PD}=0.37 \pm 0.01$ ) on day 30 , which was similar to the original size of $280.2 \pm 6.5 \mathrm{~nm}$. Meanwhile, the size of 2-NPs was approximately 297.1 $\pm 4.9 \mathrm{~nm}$ at 30 days, which had no significant difference compared to the size at day $0(273.1 \pm 1.5 \mathrm{~nm})$. Moreover, the PDI and zeta potential of both nanoparticles also kept stable during the 30 days storage (Table S8). All these facts demonstrate that 1-NPs and 2-NPs could remain stable for at least 30 days in the aqueous phase under condition of 

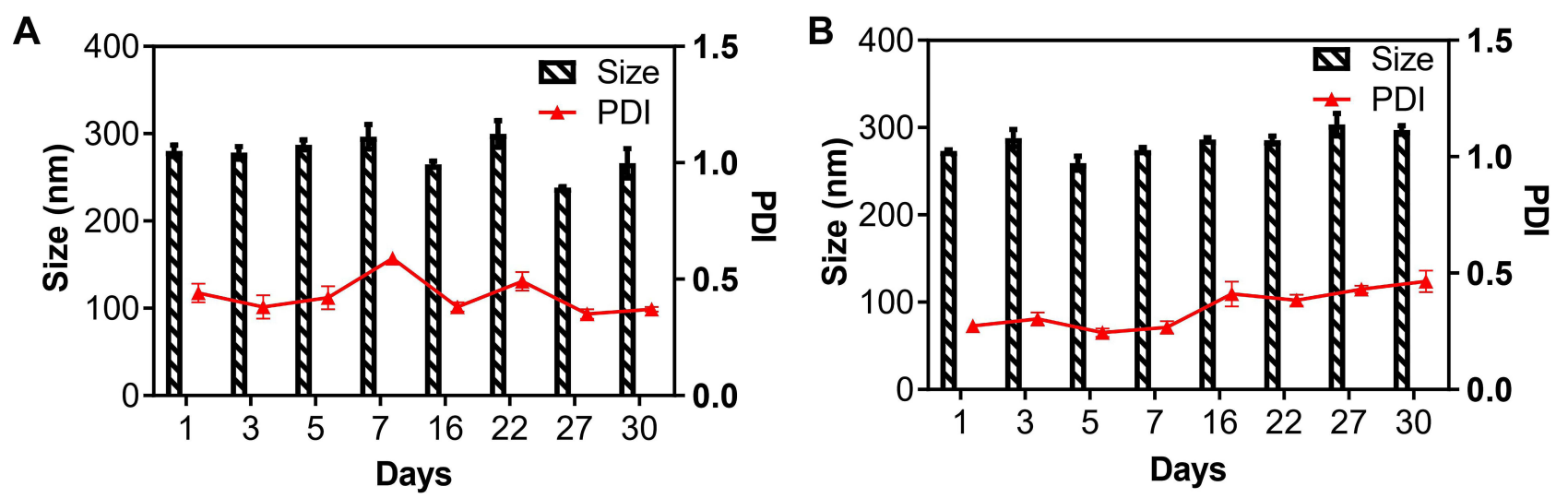

Figure 3 The particle size and PDI of (A) I-NPs and (B) 2-NPs during storage of 30 days $\left(\mathrm{pH}=7.4, \mathrm{~T}=4^{\circ} \mathrm{C}\right)$.

Abbreviations: PDI, polydispersity index; NPs, nanoparticles.

$\mathrm{T}=4^{\circ} \mathrm{C}, \mathrm{pH}=7.4$. Then, to detect the influence of temperature on stability, 1-NPs and 2-NPs were also evaluated at $25^{\circ} \mathrm{C}$ and $37^{\circ} \mathrm{C}$. Results in Tables S4, S5, S9 and S10 revealed that the increased temperature remarkably decreased the stability of NPs. The size of both 1-NPs and 2-NPs increased significantly at day five both at $25^{\circ} \mathrm{C}$ and $37^{\circ} \mathrm{C}$ accompanied with the drop Zeta potential. To further detect the influence of $\mathrm{pH}$, the change of size, PDI and zeta potential of NPs were also tested at $\mathrm{pH}=6.4$ (the $\mathrm{pH}$ in $\mathrm{TME}$ ) at $4^{\circ} \mathrm{C}$ and $37^{\circ} \mathrm{C}$. Results in Tables S6, S7, S11 and S12 manifested that low $\mathrm{pH}$ led to no significant change of 1-NPs and 2-NPs at $4^{\circ} \mathrm{C}$ in seven days. However, accelerated change of size and zeta potential of 1-NPs and 2-NPs were observed at $37^{\circ} \mathrm{C}$ $(\mathrm{pH}=6.4)$ in comparison with that in $\mathrm{pH}=7.4$. Thereby, the optimized storage conditions of the BSA NPs in this work was $\mathrm{T}=4^{\circ} \mathrm{C}, \mathrm{pH}=7.4$.

\section{Antitumor Activity in vitro}

The in vitro antitumor activities of BSA-based naproxen platinum(IV) nanoparticles 1-NPs and 2-NPs and free complexes $\mathbf{1}$ and $\mathbf{2}$ on four tumor cell lines including human ovarian cancer (SKOV-3), murine colon cancer (CT-26), human lung cancer (A549), and a cisplatinresistant cell line A549R were evaluated by MTT assay with cisplatin and oxaliplatin as reference drugs. Then, a human normal liver cell LO-2 was also evaluated and the results were given as $\mathrm{IC}_{50}$ values in Table 1 . To evaluate the effects of incubation time on antitumor activities, the $\mathrm{IC}_{50}$ values for 1, 2, 1-NPs and 2-NPs against SKOV-3 were tested after $48 \mathrm{~h}$ and $72 \mathrm{~h}$ incubation. It could be observed that the incubation time prolonging from $48 \mathrm{~h}$ to $72 \mathrm{~h}$ induces no dramatic change of the
$\mathrm{IC}_{50}$ values. Thereby, the $48 \mathrm{~h}$ incubation time was selected and applied in the following evaluation.

Free naproxen platinum(IV) hybrids $\mathbf{1}$ and $\mathbf{2}$ display effective antitumor activities to all tumor cells with $\mathrm{IC}_{50}$ values below $11.3 \mu \mathrm{M}$. Especially, complex 2 with cisplatin core exhibits promising activities $\left(\mathrm{IC}_{50} \leq 0.32 \mu \mathrm{M}\right)$ in vitro, which are significantly more effective than cisplatin and oxaliplatin. However, the free compounds possess rather poor solubility in water with high $A \log P$-values for complexes 1 (6.263) and 2 (6.182) respectively. Thereby, it is of great importance to prepare nanoparticles of such naproxen platinum(IV) complexes, which would improve solubility of drugs and further influence their activities.

As disclosed in Table 1, the BSA nanoparticles 1-NPs and 2-NPs loaded naproxen platinum(IV) complexes $\mathbf{1}$ and $\mathbf{2}$, respectively show effective antitumor activities, while the vehicle BSA exhibits no toxicity to tumor cells. Notably, all the $\mathrm{IC}_{50}$ values for 2-NPs with cisplatin platinum(IV) complex are lower than reference drug cisplatin, meanwhile 1-NPs with oxaliplatin core also display comparable or even better activities than oxaliplatin. Furthermore, 1-NPs and 2-NPs show much potential in overcoming drug resistance of A549R with low RF values of 0.4 and 0.7 , which are significantly lower than cisplatin $(\mathrm{RF}=2.6)$ and free complex $1(\mathrm{RF}=1.2)$. Then, a normal cell line $\mathrm{LO} 2$ was tested to judge the toxicities of tested NPs to normal cells. Tumor selectivity index (SI) is determined as a ratio of the $\mathrm{IC}_{50}$ of $\mathrm{LO}-2$ to the average $\mathrm{IC}_{50}$ of tumor cells. ${ }^{39,43}$ Nanoparticles possess dramatically improved SI values in comparison with the free complexes that 1-NPs and 2-NPs afford high SI values of 3.9 and 3.0 which are over 2.0-5.6 times higher than compounds $1(\mathrm{SI}=1.5)$ and $2(\mathrm{SI}=0.7)$ as well as platinum(II) drugs cisplatin $(\mathrm{SI}=1.1)$ and oxaliplatin $(\mathrm{SI}=1.0)$. These facts 
Table I Cytotoxicity Profiles of Naproxen Platinum(IV) Complexes Toward Four Carcinoma Cell Lines, and One Normal Human Cell Line Expressed as $\mathrm{IC}_{50}(\mu \mathrm{M})$

\begin{tabular}{|c|c|c|c|c|c|c|c|c|c|c|}
\hline Compounds & $\begin{array}{l}\text { ALog } \\
P^{\mathrm{a}}\end{array}$ & $\begin{array}{l}\text { SKOV-3 } \\
(48 \mathrm{~h})\end{array}$ & $\begin{array}{l}\text { SKOV-3 } \\
\text { (72 h) }\end{array}$ & $\begin{array}{l}\text { CT-26 } \\
(48 \mathrm{~h})\end{array}$ & $\begin{array}{l}\text { A549 } \\
(48 \mathrm{~h})\end{array}$ & $\begin{array}{l}\text { A549R } \\
(48 \mathrm{~h})\end{array}$ & $\mathbf{R F}^{\mathbf{b}}$ & $\begin{array}{l}\text { Average } I C_{50} \\
(48 h)^{c}\end{array}$ & $\begin{array}{l}\text { LO-2 (48 } \\
\text { h) }\end{array}$ & $\mathbf{S I}^{\mathrm{d}}$ \\
\hline $1^{30}$ & 6.263 & $11.3 \pm 0.8$ & $15.4 \pm 0.4$ & $8.2 \pm 0.6$ & $10.2 \pm 1.0$ & $12.0 \pm 0.4$ & 1.2 & 10.4 & $15.3 \pm 2.5$ & 1.5 \\
\hline I-NPs & $\mathrm{e}^{\mathrm{e}}$ & $3.8 \pm 0.5$ & $2.9 \pm 0.3$ & $2.3 \pm 0.4$ & $9.7 \pm 2.1$ & $3.6 \pm 0.7$ & 0.4 & 4.8 & $18.7 \pm 4.6$ & 3.9 \\
\hline 2 & 6.182 & $0.08 \pm 0.01$ & $0.11 \pm 0.02$ & $0.32 \pm 0.07$ & $0.14 \pm 0.04$ & $0.04 \pm 0.01$ & 0.3 & 0.14 & $0.09 \pm 0.01$ & 0.7 \\
\hline 2-NPs & I & $0.8 \pm 0.1$ & $0.6 \pm 0.1$ & $1.0 \pm 0.2$ & $1.5 \pm 0.2$ & $1.0 \pm 0.3$ & 0.7 & 1.1 & $3.3 \pm 0.4$ & 3.0 \\
\hline Npx & 2.849 & l & & $>100$ & $>100$ & $>100$ & I & I & $>100$ & I \\
\hline Vehicle & I & $>100$ & & $>100$ & $>100$ & $>100$ & I & 1 & $>100$ & 1 \\
\hline CDDP & I & $1.9 \pm 0.4$ & $1.2 \pm 0.3$ & $1.2 \pm 0.3$ & $2.8 \pm 0.6$ & $7.1 \pm 1.3$ & 2.6 & 3.0 & $3.4 \pm 1.2$ & I.I \\
\hline OLP & I & $5.9 \pm 1.3$ & $7.5 \pm 1.8$ & $4.1 \pm 0.7$ & $6.7 \pm 1.8$ & $2.4 \pm 0.6$ & 0.4 & 4.3 & $4.8 \pm 0.7$ & 1.0 \\
\hline
\end{tabular}

Notes: ${ }^{a}$ The values of Alog $P$ were predicted by Discovery Studio; ${ }^{b} \mathrm{RF}=\mathrm{IC} \mathrm{C}_{50}(\mathrm{~A} 549 \mathrm{R}) / \mathrm{IC} \mathrm{C}_{50}(\mathrm{~A} 549) ;{ }^{\mathrm{c}}$ Average $\mathrm{IC} \mathrm{C}_{50}$ values for four tumor cell lines; ${ }^{\mathrm{d}} \mathrm{SI}=\mathrm{IC} \mathrm{C}_{50}(\mathrm{LO}-2) / \mathrm{Average}$ $\mathrm{IC}_{50}$; ${ }^{\mathrm{e}}$ Not tested or not calculated.

Abbreviations: NPs, nanoparticles; NPx, naproxen; RF, resistant factor; SI, selectivity index, CDDP, cisplatin; OLP, oxaliplatin.

indicate the low toxicities of the prepared BSA nanoparticles to normal cells.

Ultimately, BSA based naproxen platinum(IV) nanoparticles 1-NPs and 2-NPs display prominent antitumor activities to all tested tumor cells and exhibit much potential in overcoming drug resistance of cisplatin. Both nanoparticles show low toxicities to normal cells in contrast to cisplatin and oxaliplatin as well as the free platinum(IV) complexes $\mathbf{1}$ and 2. The antitumor activities in vivo and action mechanism of the NPs were investigated in the following experiments.

\section{Antitumor Efficacy in vivo}

Colonic carcinoma as one of the most common cancers worldwide is a major cause of morbidity and mortality. ${ }^{50}$ Platinum drugs occupy an important position in colonic carcinoma treatment. In addition, naproxen has been proven to be favorable for treating colonic carcinoma to combine with platinum drugs. Herein, BALB/c mice bearing CT-26 homograft tumors were selected as models to study the effectiveness of BSA nanoparticles 1-NPs and 2-NPs to compare with free naproxen platinum(IV) complexes $\mathbf{1}$ and 2, using cisplatin and oxaliplatin as reference drugs. Complex 1 and 1-NPs with oxaliplatin core and oxaliplatin were administrated at dosage of $4 \mathrm{mg} \mathrm{Pt} / \mathrm{kg}$. Then, cisplatin was given at a low dosage of $2 \mathrm{mg} \mathrm{Pt} / \mathrm{kg}$ taking its highly toxic properties in consideration, and the cisplatin-derived compound 2 and 2-NPs were also administrated at the same dosage. The nanoparticles 1-NPs, 2-NPs and platinum(II) drugs cisplatin and oxaliplatin were administrated via intravenous injection (i.v.) with saline as blank, while free complexes $\mathbf{1}$ and $\mathbf{2}$ were administrated via intraperitoneal injection (i.p.) for their poor solubility in saline.

The results in Figure 4 showed that nanoparticles 1-NPs, 2-NPs show remarkable inhibition of the tumor growth in vivo in contrast to saline group $(P<0.001)$, which are relatively more effective than the free compounds $\mathbf{1}$ and $\mathbf{2}$ $(P<0.05)$, and this trend is contrary to the results in vitro. Tumor for the saline group rapidly grows to $1586 \mathrm{~mm}^{3}$ in 15 days (Figure 4A and $\mathrm{C}$ ), while the volumes of reference drugs oxaliplatin and cisplatin groups are $477 \mathrm{~mm}^{3}$ and $399 \mathrm{~mm}^{3}$. Nanoparticles 1-NPs and 2-NPs suppress the tumor volumes to $654 \mathrm{~mm}^{3}$ and $562 \mathrm{~mm}^{3}$ effectively, which are smaller than the corresponding free complex treated groups $1\left(1041 \mathrm{~mm}^{3}, P<0.001\right)$ and $2\left(836 \mathrm{~mm}^{3}\right.$, $P<0.05)$ respectively. Then, tumor weight was measured after the mice were sacrificed and given in Figure 4B. Tumor growth inhibition rate (TGI) as an important index to judge effectiveness of antitumor drugs was calculated as a ratio of tumor weight of the drug-treated group to that of the saline group, and was depicted above the columns. Nanoparticles 1-NPs and 2-NPs show higher TGI of $64.7 \%$ and $58.9 \%$ than free complexes 1 (TGI $=45.8 \%$, $P<0.05)$ and 2 (TGI $=41.2 \%, P<0.05)$. The hematoxylin and eosin (H\&E) staining of tumor tissues in Figure 4D shows that 1-NPs, 2-NPs and free compound $\mathbf{1}$ and $\mathbf{2}$ induce obvious apoptosis and necrosis in tumor tissues in comparison with saline, and this evidence is similar to that in the cisplatin and oxaliplatin treated groups. 

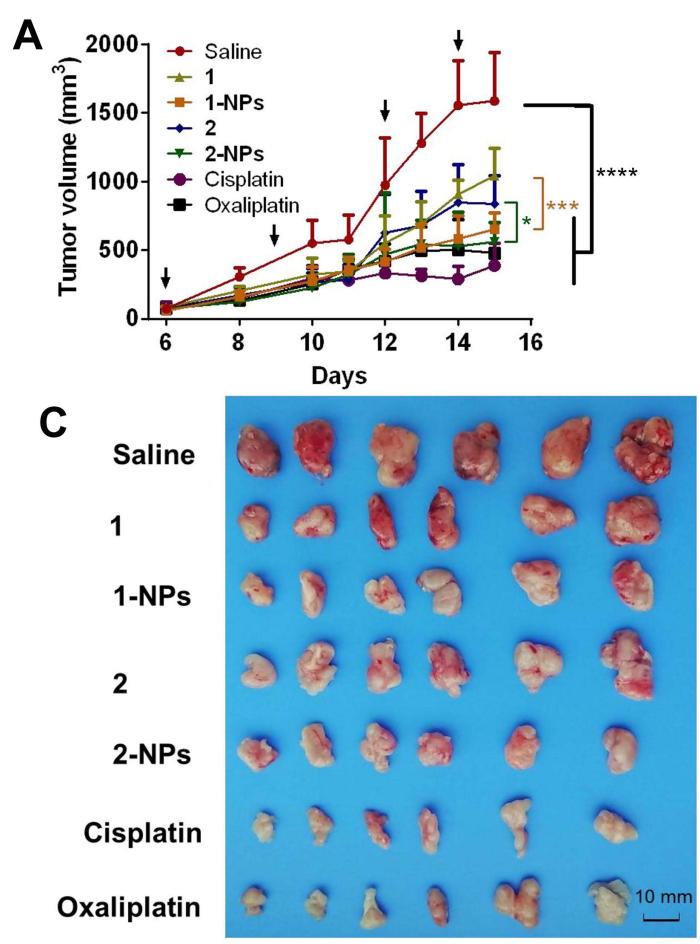

B

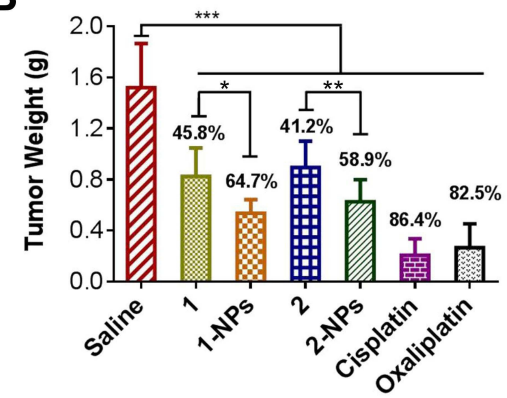

D 1 1 1-NPS

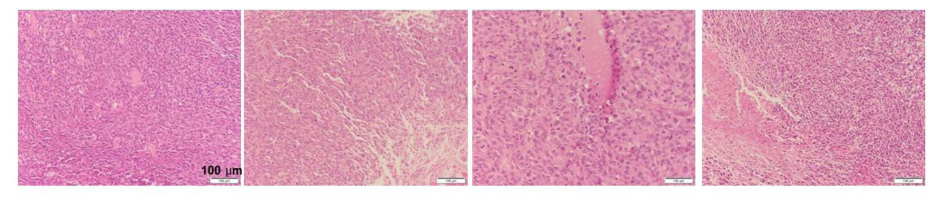

Saline Cisplatin Oxaliplatin

Figure 4 In vivo antitumor activities of nanoparticles and free naproxen platinum(IV) compounds to CT-26 homograft tumors in BALB/c mice. Dosage: $4 \mu \mathrm{g}$ Pt/kg for I-NPs (i.v.), I (i.p.) and oxaliplatin (i.v.); $2 \mu \mathrm{g}$ Pt/kg for 2-NPs (i.v.), 2 (i.p.) and cisplatin (i.v.). Drugs were injected on days 6, 9, 12 , I4 posttumor inoculation as indicated by the arrows in Figure 4A. (A) Tumor growth as a function of time. (B) Tumor weight in each group at the end of the experiment. The TGI of the tested drugs are depicted above the column (TGI=tumor weight of drug treated group/tumor weight of saline group). (C) The images of the tumors at the end of the experiment. (D) The H\&E staining of slices from tumor tissues.

Notes: Results are presented as the mean \pm SD $(n=6) . * P<0.05, * P<0.05, * * * p<0.001$, $* * * * P<0.00$ I.

Abbreviations: NPs, nanoparticles; i.p., intraperitoneal; i.v., intravenous; TGI, growth inhibition rate; H\&E, hematoxylin and eosin.

\section{Toxicity in vivo}

The potential toxicities of the nanoparticles were assessed systematically during the treatment in vivo to compare with free complexes, cisplatin and oxaliplatin. Body weight as a primary indicator measuring toxic properties of drugs was monitored and supplied in Figure 5A. It is disclosed that cisplatin (2 mg Pt/kg) and oxaliplatin (4 mg $\mathrm{Pt} / \mathrm{kg}$ ) possess the most serious toxicity to mice by inducing body weight loss of $19.8 \%$ and $16.1 \%$ in comparison with the saline group at the end of the experiment $(P<0.01)$. Moreover, anorexia and dyskinesia, which associate with toxicity, were observed in the cisplatin and oxaliplatin treated groups for approximately eight hours after administration. In contrast, the tested groups 1-NPs and 2-NPs as well as free complexes 1 and $\mathbf{2}$ induce no apparent signs of muscle loss, dehydration, anorexia, locomotor impairment or other unusual symptoms during the treatment, and cause rather lower weight loss of mice $(0.2 \%-10.7 \%)$ than cisplatin and oxaliplatin $(P<0.01)$. These facts reflect the lower toxic effects of naproxen platinum(IV) nanoparticles and free compounds in comparison with platinum(II) drugs. Furthermore, nanoparticles possess reduced toxic properties in comparison with free naproxen platinum(IV) complexes that the loss of body weight for nanoparticle 2-NPs $(5.6 \%)$ is rather lower than free compound $2(10.6 \%)(P<0.001)$, meanwhile 1-NPs $(2 \mathrm{mg} \mathrm{Pt} / \mathrm{kg})$ also induces relatively lower body weight loss $(0.2 \%)$ than free complex $1(2.5 \%)$.

The toxic effects of drugs on the organs including heart, liver, spleen, lung and kidney were evaluated by $\mathrm{H} \& \mathrm{E}$ staining assay and organ weight indexes. The nanoparticles 1-NPs, 2-NPs, and free complexes 1, 2 as well as the reference drugs cisplatin and oxaliplatin cause no appreciable histological differences of the organs to compare with the saline group (Figure 5C). However, the organ weight indexes in Figure S4 as ratios of organ weight to body weight reveal remarkable suppressions of spleen induced by cisplatin and oxaliplatin in comparison with the saline group $(P<0.01)$, which indicates the spleen damage caused by the platinum(II) drugs. Meanwhile nanoparticles 1-NPs and 2-NPs improve spleen indexes to some extent, and free 


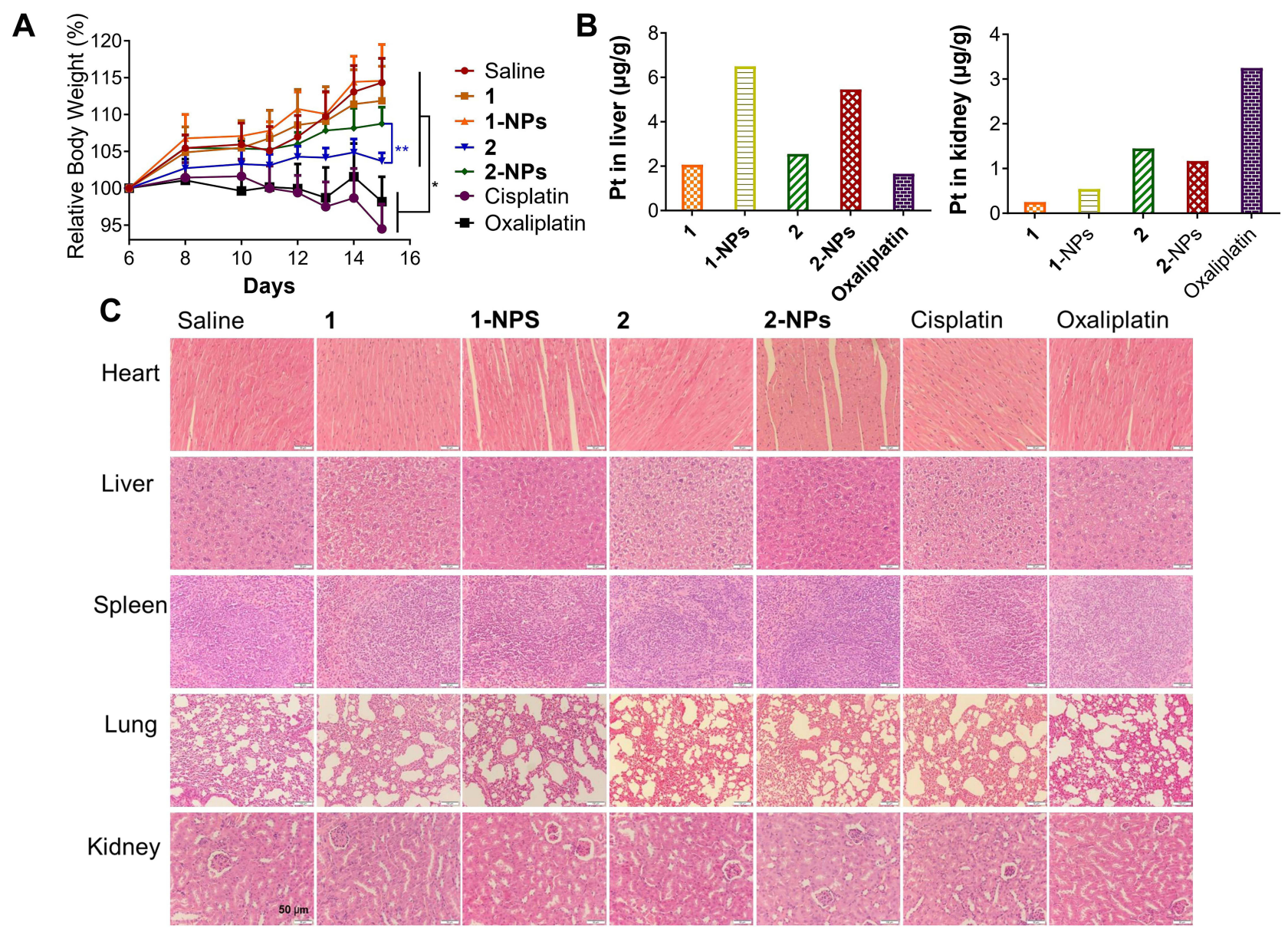

Figure $\mathbf{5}$ In vivo toxicities of tested compounds and nanoparticles to BALB/c mice. (A) The body weight of the mice during the treatment. (B) Drug accumulation in liver and kidney. (C) The H\&E staining of slices from heart, liver, spleen, lung and kidney.

Notes: $* P<0.01$, $* * P<0.001$.

Abbreviations: NPs, nanoparticles; H\&E, hematoxylin and eosin.

complexes $\mathbf{1}$ and $\mathbf{2}$ induce no significant influences. These results are probably attributed to the reduced toxic properties of the nanoparticles. Then, the variations of heart, liver, lung and kidney indexes for all tested drugs are negligible in contrast to saline.

It is widely proven that nephrotoxicity, hepatotoxicity and neurotoxicity are the key factors influencing the toxicities of platinum drugs. The drug accumulation in liver and kidney were also detected. Results in Figure 5B reveal that the BSA nanoparticles have rather different distribution in liver and kidney with the free naproxen platinum(IV) compounds. The platination levels of 1-NPs and 2-NPs in liver are higher than free compounds $\mathbf{1}$ and 2 as well as oxaliplatin. Meanwhile, oxaliplatin accumulates at a remarkably higher level in the kidney than naproxen platinum(IV) complexes and nanoparticles. The different distributions manifest the different metabolic pathways of the BSA NPs with platinum(II) drugs in vivo, which would further influence toxicities. Subsequently, the nephrotoxicity and hepatotoxicity were detected by evaluating aspartate aminotransferase (AST), alanine aminotransferase (ALT), blood urea nitrogen (BUN) and creatinine (CRE) levels in serum. Noteworthy, oxaliplatin causes significant enhanced ALT and AST levels in comparison with saline indicating its impacts on liver function (Figure S5), although no obvious histological differences or liver index change are observed. In contrast, nanoparticles 1-NPS, 2-NPS display no significant effects on ALT and AST levels in serum. Then, free complexes $\mathbf{1}$ and $\mathbf{2}$ cause relatively high AST levels in comparison with 1-NPS and 2-NPS indicating that the BSA nanoparticles of naproxen platinum(IV) complexes exhibit lower liver toxicity than the free compounds as well as oxaliplatin. As for 

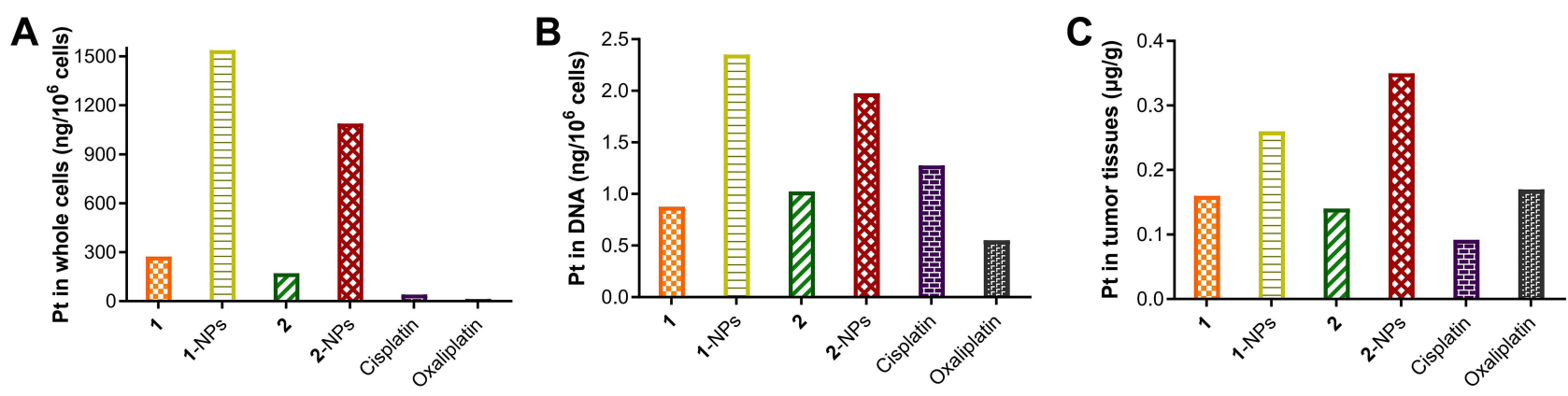

Figure 6 Accumulation of nanoparticles I-NPs, 2-NPs and complexes I, 2 in (A) CT-26 cells, (B) DNA after treatment of $10 \mathrm{~h}$ at concentration of I00 $\mu$ M in vitro and in (C) tumor tissues in vivo.

Abbreviation: NPs, nanoparticles.

CRE and BUN, there are no obvious differences observed in the tested groups with the saline group. Summarily, BSA NPs of naproxen platinum(IV) hybrids display reduced toxic effects in comparison with platinum(II) drugs in vivo, especially to the spleen and liver.

\section{Tumor Target Properties}

Tumor target properties of chemotherapeutic drugs influence their antitumor activities and toxicities dramatically. To evaluate the tumor target properties of nanoparticles, the accumulation of 1-NPs and 2-NPs in CT-26 cells in vitro and in tumor tissues in vivo were tested by ICPMS to compare with compounds $\mathbf{1}, \mathbf{2}$, cisplatin, oxaliplatin. Moreover, platinum drugs exert antitumor activities mainly through coordination to DNA via the platinum fragment. Therefore, the platinum accumulation in DNA of CT-26 cells was also evaluated. Results in Figure 6 manifest that nanoparticles 1-NPs and 2-NPs significantly improve the drug accumulation both in CT-26 cells in vitro and in tumor tissues in vivo in comparison with free compounds $\mathbf{1}$ and $\mathbf{2}$ as well as the platinum(II) drugs cisplatin and oxaliplatin. Nanoparticles 1-NPs and 2-NPs lead to 5.6 and 6.4 folds enhanced uptake in whole cells in contrast to 1 and 2, which are over 37.4 and 26.5 times higher than cisplatin and oxaliplatin (Figure 6A). Subsequently, 1-NPs and 2-NPs also lead to relatively higher platination level in DNA than free complexes 1, 2 and platinum(II) drugs (Figure 6B). These results also supply direct evidence of the DNA damage caused by the platinum(II) complex released from the nanoparticles. Notably, the accumulation of 1-NPs and 2-NPs in tumor tissues are 1.6 and 2.5 folds higher than $\mathbf{1}$ and $\mathbf{2}$, respectively (Figure 6C), which are also higher than cisplatin and oxaliplatin.

\section{COX Inhibition}

$\mathrm{COX}$ as the most important inflammatory factor has appeared as a promising target for reducing tumorassociated inflammation during the cancer chemotherapy treatment. Thereby, the COX inhibitory properties of naproxen platinum(IV) complexes $\mathbf{1}$ and $\mathbf{2}$, which could be released by 1-NPs and 2-NPs, were tested with naproxen and celecoxib as reference drugs. The reduced systems of complexes $\mathbf{1}$ and $\mathbf{2}$ (compound-AsA) were also evaluated, which were prepared by the incubation of compound solutions in the presence of AsA (1 mM) for $48 \mathrm{~h}$ to allow the platinum(IV) totally converting to divalent form. Results in Figure 7 manifest that celecoxib could effectively inhibit

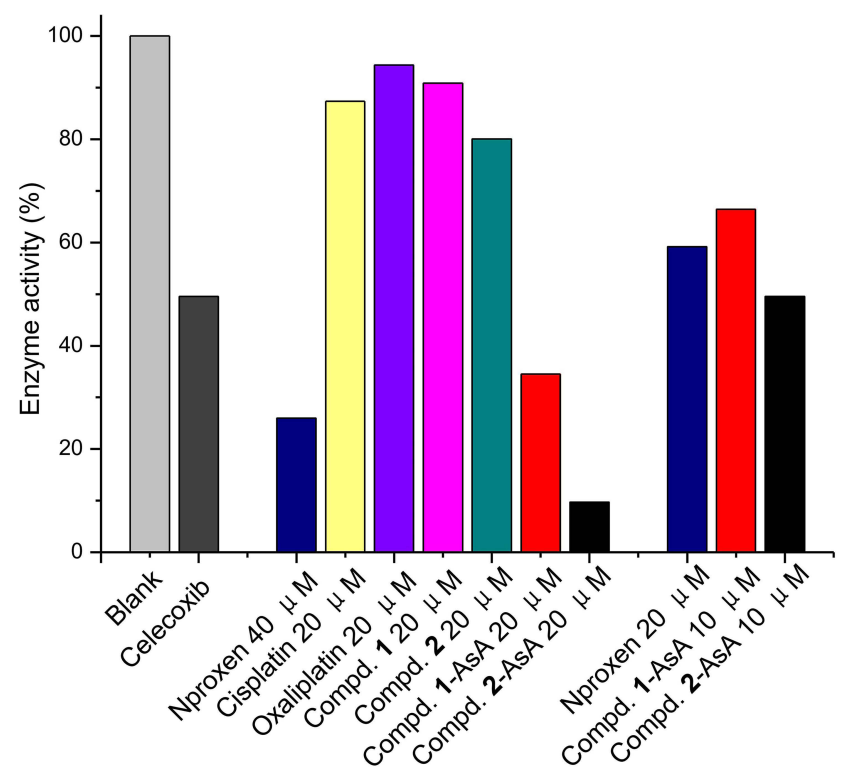

Figure 7 The inhibition of compounds I, 2, naproxen and the reduced systems of complexes I, 2 (Compd-AsA) at different concentrations to COX-2 with celecoxib as reference drug.

Abbreviation: COX-2, cyclooxygenase-2. 
the activity of COX-2 to $49.5 \%$ at concentration of 100 nM. Naproxen platinum(IV) complexes $\mathbf{1}$ and $\mathbf{2}$ exhibit negligible inhibitions of COX-2 in tetravalent form even at high concentration of $20 \mu \mathrm{M}$, meanwhile their reduced systems compound 1-AsA and compound 2-AsA display prominent COX-2 inhibition of $65.5 \%$ and $90.3 \%$, which are similar to naproxen (74.0\%). Furthermore, the COX-2 inhibitory competence of the reduced naproxen platinum(IV) complexes is in a dose-dependent manner that low concentration of 5 $\mu \mathrm{M}$ leads to significantly less effective COX-2 inhibition than that of high dosage of $20 \mu \mathrm{M}$. Thereby, naproxen platinum(IV) complexes $\mathbf{1}$ and $\mathbf{2}$ as well as the nanoparticles 1-NPs and 2-NPs exert effective COX-2 inhibitory properties after reduction and release naproxen, which would decrease tumor-associated inflammation in tumor tissues and further increase antitumor activities.

\section{iNOS Suppression and NO Production Inhibition}

Nitric oxide (NO) was an important pro-inflammatory mediator in the regulation of inflammation progresses. Accumulated evidence has indicated that excessive production of NO in the tumor tissues could promote the development of inflammation and eventually lead to inflammatory tissue damage and further stimulate tumor growth and migration by inducing cell proliferation, reducing immune surveillance and promoting angiogenesis. ${ }^{51-}$ 55 Herein, LPS induced RAW 264.7 macrophages, which

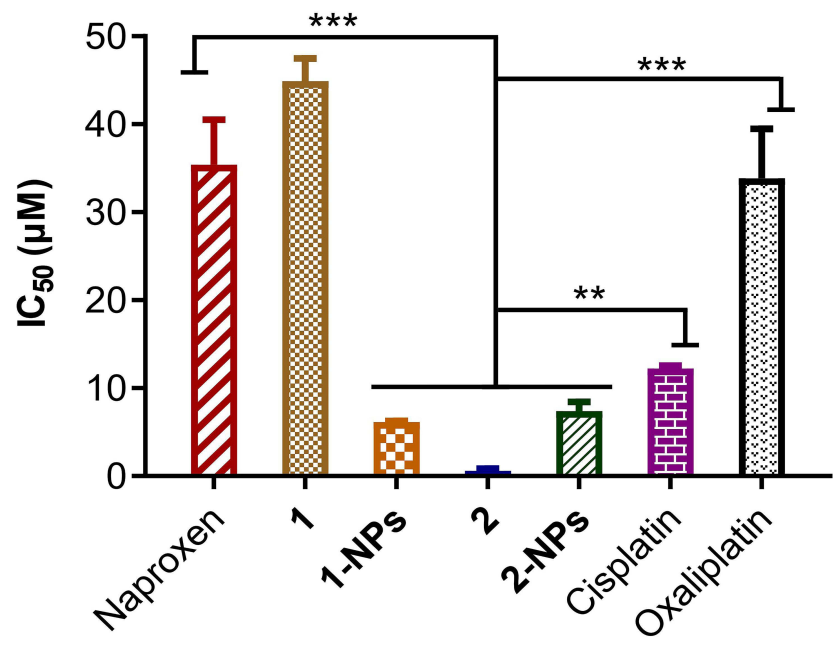

Figure $8 \mathrm{NO}$ production inhibition of drugs I, 2, I-NPs and 2-NPs and reference drugs naproxen, cisplatin and oxaliplatin in LPS induced RAW 264.7. Notes: Results are presented as the mean \pm SD. $* * P<0.01$, $* * * P<0.001$. Abbreviations: NPs, nanoparticles; LPS, lipopolysaccharide. were widely used as a model for studying the inflammatory responses, ${ }^{56}$ were applied to evaluate the effects of naproxen platinum(IV) nanoparticles on the NO production and detect their potential effects on anti-inflammation. Results in Figure 8 indicate that naproxen platinum(IV) nanoparticles 1-NPs and 2-NPs could inhibit production of NO in RAW 264.7 macrophages, which are significantly more effective than naproxen, cisplatin and oxaliplatin. The conversion of complex 1 to nanoparticles 1-NPs improve the activities effectively, while both complex 2 and 2-NPs display satisfactory inhibition of NO production.

The inducible nitric oxide synthase (iNOS) as a calcium-independent isoform of nitric oxide synthase highly expresses in many tumors, and is the crucial enzyme responsible for the production of NO, which could lead to high levels of NO in the micromolar range. Moreover, there is emerging evidence showing that iNOS plays a central role in the process of tumor initiation and/ or development. ${ }^{57,58}$ Thus, the expressions of iNOS in tumor issues treated by $\mathbf{1 - N P s}$ and free compound $\mathbf{1}$ were detected by immunohistochemistry. Results in Figure 9 reflect that oxaliplatin significantly upregulates iNOS in tumor tissues during its antitumor progress. Whereas, the expressions of iNOS in 1-NPs treated group is significantly lower than that of oxaliplatin $(P<0.001)$. Furthermore, 1-NPs is also more effective than the free drug $1(P<0.001)$ in iNOS inhibition, which is in line with the NO production inhibition in vitro.

Accordingly, the title naproxen platinum(IV) nanoparticle drugs show much potential in inhibiting NO production and iNOS expression, which would further influence tumor-associated inflammation.

\section{Detection of MMP-9}

MMPs are widely found in inflammation and various tumor tissues, and display pivotal roles in influencing tumor growth, invasion and metastasis. Moreover, MMPs play a synergic function with COXs in promotion of inflammation in tumors. MMPs have been considered as potential diagnostic and prognostic biomarkers in many types and stages of cancer. ${ }^{59,60}$ Herein, the expressions of MMP-9 in tumor tissues of 1-NPs, 1, oxaliplatin and saline groups were immunohistochemically stained and given as Figure 10. MMP-9 overexpresses in saline group with a mean optical density of $16.3 \pm 1.9 \%$. Meanwhile, 1 and 1-NPs remarkably decrease the expression of MMP-9 to $1.9 \pm 0.5 \%$ and $2.0 \pm 0.8 \%$ respectively, 


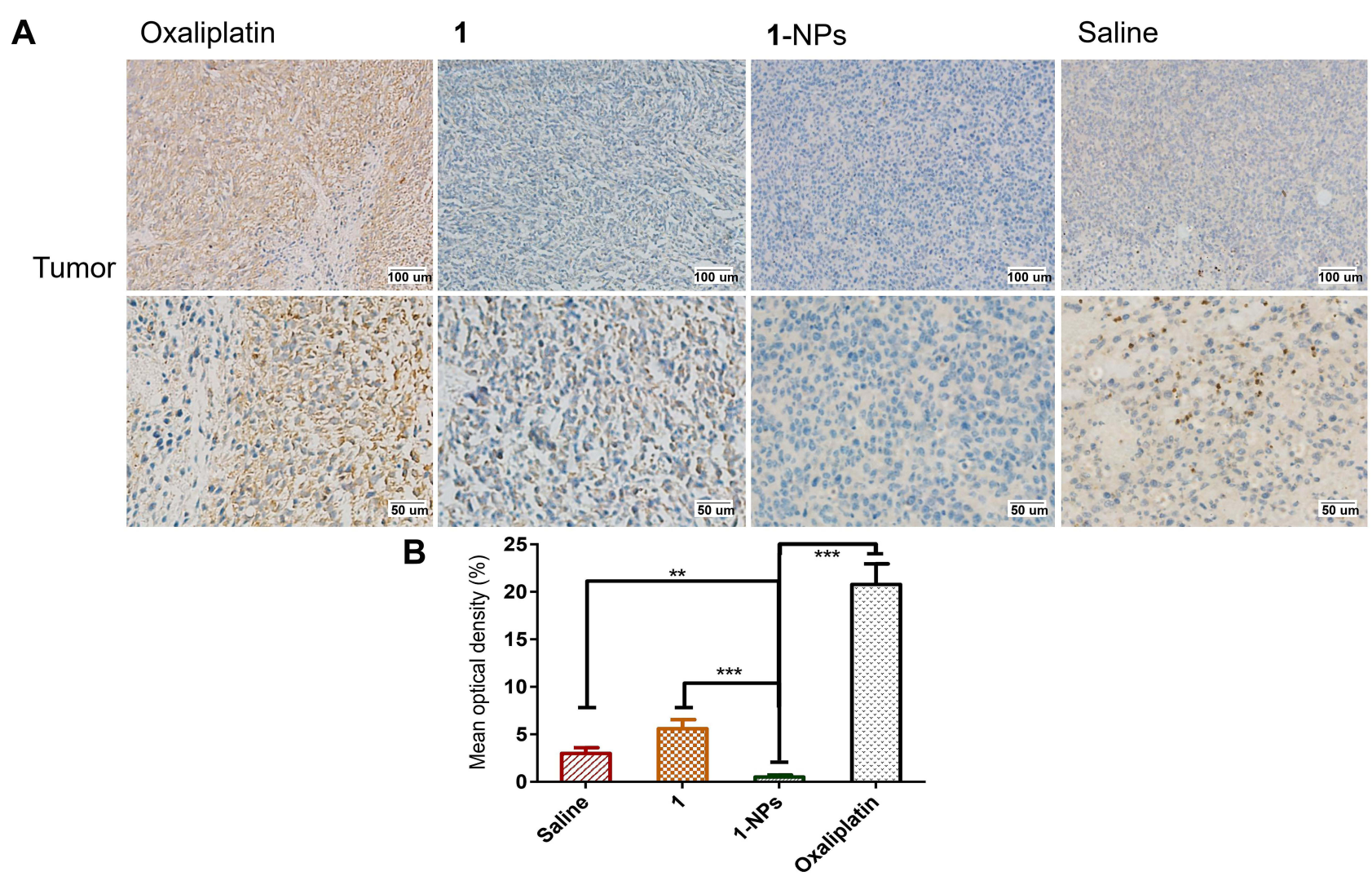

Figure 9 Photography of immunohistochemical staining of iNOS in tumor tissues from mice treated by I, I-NPs, oxaliplatin and saline. (A) Representative micrographs. (B) Quantified data of immunohistochemistry analysis.

Notes: Results are presented as the mean $\pm S D(n=5)$. **P<0.0I, ***P<0.00I.

Abbreviations: iNOS, inducible nitric oxide synthase; NPs, nanoparticles.

which are significantly lower than oxaliplatin (6.5 $\pm 0.5 \%)$. The promising MMP-9 inhibitory potential of naproxen platinum(IV) nanoparticles would put much influence on reducing inflammation in tumor tissues and improving antitumor activities.

\section{Conclusion}

In conclusion, two BSA-encapsulated nanoparticles 1-NPs and 2-NPs of naproxen platinum(IV) complexes $\mathbf{1}$ and $\mathbf{2}$ were prepared and evaluated for antitumor activities in vitro and in vivo. The nanoparticles possessed relatively uniform size and good stability for 30 days in aqueous solution $\left(\mathrm{T}=4^{\circ} \mathrm{C}, \mathrm{pH}=7.4\right)$. Both of them display effective antitumor activities in vitro, and exhibit great potential in overcoming drug resistance of cisplatin with resistant factors $(\mathrm{RF}<0.68)$ significantly lower than cisplatin $(\mathrm{RF}=2.57)$. Moreover, 1-NPs and 2-NPs accumulate at higher levels in whole tumor cells, DNA and tumor tissues than cisplatin and oxaliplatin as well as free platinum(IV) complexes $\mathbf{1}$ and $\mathbf{2}$, and show low toxicity with high tumor selective indexes of 3.0 and 3.9 , which are significantly more promising than cisplatin $(\mathrm{SI}=1.1)$ and oxaliplatin $(\mathrm{SI}=1.0)$. Furthermore, these two nanoparticles play superior tumor growth suppression in vivo with high TGI of $64.7 \%$ and $58.9 \%$ in contrast to free compounds $\mathbf{1}$ and $\mathbf{2}(45.8 \%, 41.7 \%)$, which are comparable to that of cisplatin and oxaliplatin, and induce lower toxic influences than platinum(II) drugs especially to the spleen and liver. The naproxen platinum(IV) nanoparticles display antitumor activities by a symmetric mechanism (Figure 1) that nanoparticles target tumor cells and would release naproxen platinum(IV) complexes $\mathbf{1}$ and $\mathbf{2}$ in cytoplasm. Then the platinum(II) core would be released after reduction, and further conjunct with DNA to cause serious DNA damage. The further mechanism detections in vitro and in vivo disclose that the inflammation in tumor tissues could be reduced through the suppression of COX-2, iNOs, MMP-9 and the decrease of NO production, which would increase the sensitivity of tumor cells to platinum 


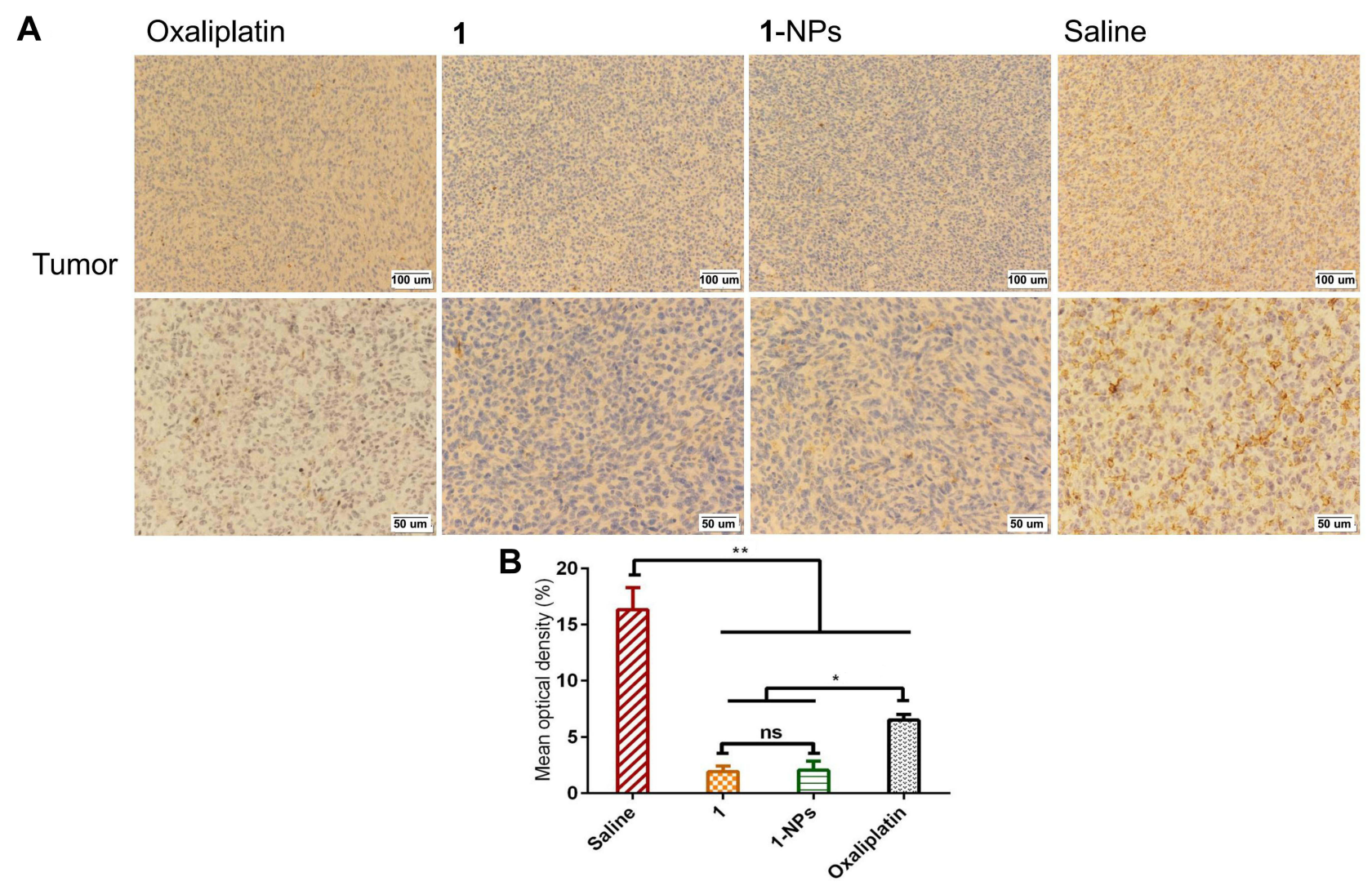

Figure 10 Photography of immunohistochemical staining of MMP-9 in tumor tissues from mice treated by I, I-NPs oxaliplatin and saline. (A) Representative micrographs. (B) Quantified data of immunohistochemistry analysis.

Notes: Results are presented as the mean $\pm S D(n=5) . * P<0.00 I, * * P<0.001$, ns, no significant difference.

Abbreviations: MMP-9, metalloproteinase-9; NPs, nanoparticles.

drugs, prevent the development of cancer and enhance the antitumor activities of the nanoparticles. These encouraging results highlight the value of naproxen platinum(IV) nanoparticles 1-NPs and 2-NPs as antitumor agents, and further investigations based on such drugs are underway in our laboratory.

\section{Acknowledgments}

This work was supported by National Natural Science Foundation of China (No. 21807056), Natural Science Foundation of Shandong Province (No. ZR2020KH005), National Science and Technology Major Project (No. 2017ZX09201-003) and Taishan Scholar Research Foundation. This work was also technically supported by Shandong Province Collaborative Innovation Center for Antibody Drugs, Shandong Province Engineering Research Center for Nanomedicine and Drug Delivery Systems, and Shandong Province Engineering Laboratory of Anti-viral Drugs.

\section{Disclosure}

Zhengping Wang is an employee of Liaocheng HighTech Biotechnology Co., Ltd, Liaocheng, China. The authors report no other potential conflicts of interest in this work.

\section{References}

1. Siegel RL, Miller KD, Jemal A. Cancer statistics, 2019. CA Cancer J Clin. 2019;69(1):7-34. doi:10.3322/caac.21551

2. Chen W, Zheng R, Baade PD, et al. Cancer statistics in China, 2015. CA Cancer J Clin. 2016;66(2):115-132. doi:10.3322/caac.21338

3. Peng Y, Chen L, Ye S, et al. Research and development of drug delivery systems based on drug transporter and nano-formulation. Asian J Pharm Sci. 2020;15(2):220-236. doi:10.1016/j.ajps.2020. 02.004

4. Fang J, Nakamura H, Maeda $H$. The EPR effect: unique features of tumor blood vessels for drug delivery, factors involved, and limitations and augmentation of the effect. Adv Drug Deliv Rev. 2011;63 (3):136-151. doi:10.1016/j.addr.2010.04.009

5. Zhao YP, Zhao YN, Ma QS, et al. Carrier-free, dual-functional nanorods via self-assembly of pure drug molecules for synergistic chemo-photodynamic therapy. Int J Nanomed. 2019;14:8665-8683. doi:10.2147/IJN.S224704 
6. Johnstone TC, Suntharalingam K, Lippard SJ. The next generation of platinum drugs: targeted $\mathrm{Pt}(\mathrm{II})$ agents, nanoparticle delivery, and Pt(IV) prodrugs. Chem Rev. 2016;116(5):3436-3486. doi:10.1021/ acs.chemrev.5b00597

7. Li Y, Sun Z, Cui Y, et al. Oxaliplatin derived monofunctional triazole-containing platinum(II) complex counteracts oxaliplatin-induced drug resistance in colorectal cancer. Bioorg Chem. 2021;107:104636. doi:10.1016/j.bioorg.2021.10 4636

8. Wang XY, Wang XH, Guo ZJ. Functionalization of platinum complexes for biomedical applications. Acc Chem Res. 2015;48 (9):2622-2631. doi:10.1021/acs.accounts.5b00203

9. Callari M, Aldrich-Wright JR, de Souza PL, Stenzel MH. Polymers with platinum drugs and other macromolecular metal complexes for cancer treatment. Prog Polym Sci. 2014;39(9):1614-1643. doi:10.1016/j.progpolymsci.2014.05.002

10. Newman M, Colbern GT, Working PK, Engbers C, Amantea MA. Comparative pharmacokinetics, tissue distribution, and therapeutic effectiveness of cisplatin encapsulated in long-circulating, pegylated liposomes (SPI-077) in tumor-bearing mice. Cancer Chemother Pharmacol. 1999;43(1):1-7. doi:10.1007/s00280005 0855

11. Ma J, Wang Q, Huang Z, et al. Glycosylated platinum(IV) complexes as substrates for glucose transporters (GLUTs) and organic cation transporters (OCTs) exhibited cancer targeting and human serum albumin binding properties for drug delivery. J Med Chem. 2017;60(13):5736-5748. doi:10.1021/acs. jmedchem. $7 \mathrm{~b} 00433$

12. Tan XX, Li GS, Wang QP, Wang BQ, Li DC, Wang PG. Small molecular platinum(IV) compounds as antitumor agents. Prog Chem. 2018;30(6):831-846. doi:10.7536/PC171212

13. Karimi M, Bahrami S, Ravari SB, et al. Albumin nanostructures as advanced drug delivery systems. Expert Opin Drug Deliv. 2016;13 (11):1609-1623. doi:10.1080/17425247.2016.1193149

14. Parodi A, Miao J, Soond SM, Rudzińska M, Zamyatnin AA Jr. Albumin nanovectors in cancer therapy and imaging. Biomolecules. 2019;9(6):218. doi:10.3390/biom9060218

15. Hassanin I, Elzoghby A. Albumin-based nanoparticles: a promising strategy to overcome cancer drug resistance. Cancer Drug Resist. 2020;3:930-946. doi:10.20517/cdr.2020.68

16. Adams JD, Flora KP, Goldspiel BR, Wilson JW, Arbuck SG, Finley R. Taxol: a history of pharmaceutical development and current pharmaceutical concerns. J Natl Cancer Inst. 1993;15:141-147.

17. Nosrati H, Sefidi N, Sharafi A, Danafar H, Manjili HK. Bovine serum albumin (BSA) coated iron oxide magnetic nanoparticles as biocompatible carriers for curcumin-anticancer drug. Bioorg Chem. 2018;76:501-509. doi:10.1016/j.bioorg.2017.12.033

18. Nosrati H, Danafar H, Rezaeejam H, Gholipour N, RahimiNasrabadi M. Evaluation radioprotective effect of curcumin conjugated albumin nanoparticles. Bioorg Chem. 2020;100:103891. doi:10.1016/j.bioorg.2020.103891

19. Ding $\mathrm{C}, \mathrm{Xu} \mathrm{Y}$, Zhao Y, Zhong H, Luo X. Fabrication of BSA@AuNC-based nanostructures for cell fluoresce imaging and target drug delivery. ACS Appl Mater Interfaces. 2018;10 (10):8947-8954. doi:10.1021/acsami.7b18493

20. Zhao Y, Cai C, Liu M, et al. An organic solvent-free technology for the fabrication of albumin-based paclitaxel nanoparticles for effective cancer therapy. Colloid Surface B. 2019;183:110394. doi:10.1016/j. colsurfb.2019.110394

21. Zheng YR, Suntharalingam K, Johnstone TC, et al. Pt(IV) prodrugs designed to bind non-covalently to human serum albumin for drug delivery. J Am Chem Soc. 2014;136(24):8790-8798. doi:10.1021/ ja5038269

22. Hanahan D, Weinberg RA. Hallmarks of cancer: the next generation. Cell. 2011;144(5):646-674. doi:10.1016/j.cell.2011.02.013
23. Nisticò P, Ciliberto G. Biological mechanisms linked to inflammation in cancer: discovery of tumor microenvironment-related biomarkers and their clinical application in solid tumors. Int $J$ Biol Marker. 2020;35(1_suppl):8-11. doi:10.1177/ 1724600820906155

24. Leon-Cabrera S, Schwertfeger KL, Terrazas LI. Inflammation as a target in cancer therapy. Mediators Inflamm. 2019;2019:1971698. doi: $10.1155 / 2019 / 1971698$

25. Zhang J, Zhang Y, Wang Q, et al. Interleukin-35 in immune-related diseases: protection or destruction. Immunology. 2019;157(1):13-20. doi:10.1111/imm.13044

26. Cheng Q, Shi H, Wang H, Min Y, Wang J, Liu Y. The ligation of aspirin to cisplatin demonstrates significant synergistic effects on tumor cells. Chem Commun. 2014;50(56):7427-7430. doi:10.1039/ $\mathrm{c} 4 \mathrm{cc} 00419 \mathrm{a}$

27. Pathak R, Marrache S, Choi JH, Berding TB, Dhar S. The prodrug platin-A: simultaneous release of cisplatin and aspirin. Angew Chem Int Ed Engl. 2014;53(7):1963-1967. doi:10.1002/anie.201308899

28. Neumann W, Crews BC, Sárosi MB, et al. Conjugation of cisplatin analogues and cyclooxygenase inhibitors to overcome cisplatin resistance. ChemMedChem. 2015;10(1):183-192. doi:10.1002/ cmdc. 201402353

29. Ravera M, Zanellato I, Gabano E, et al. Antiproliferative activity of $\mathrm{Pt}(\mathrm{IV})$ conjugates containing the non-steroidal anti-inflammatory drugs (NSAIDs) ketoprofen and naproxen. Int J Mol Sci. 2019;20 (12):3074. doi:10.3390/ijms20123074

30. Li G, Zhang J, Liu Z, et al. Development of a series of 4-hydroxycoumarin platinum(IV) hybrids as antitumor agents: synthesis, biological evaluation and action mechanism investigation. J Inorg Biochem. 2019;194:34 43. doi:10.1016/j.jinorgbio.2019.02.011

31. Wang Q, Chen Y, Li G, et al. Synthesis and evaluation of bi-functional 7-hydroxycoumarin platinum(IV) complexes as antitumor agents. Bioorg Med Chem. 2019;27(10):2112-2121. doi:10.1016/j.bmc.2019.04.009

32. Tan J, Li C, Wang Q, et al. A carrier-free nanostructure based on platinum(IV) prodrug enhances cellular uptake and cytotoxicity. Mol Pharmaceutics. 2018;15(4):1724-1728. doi:10.1021/acs.molpharmaceut. $8 \mathrm{~b} 00070$

33. Spector D, Krasnovskaya O, Pavlov K, et al. Pt(IV) prodrugs with NSAIDs as axial ligands. Int J Mol Sci. 2021;22(8):3817. doi:10.3390/ ijms 22083817

34. Zanellato I, Bonarrigo I, Ravera M, Gabano E, Gust R, Osella D. The hexacarbonyldicobalt derivative of aspirin acts as a CO-releasing NSAID on malignant mesothelioma cells. Metallomics. 2013;5 (12):1604-1613. doi:10.1039/c3mt00117b

35. Curci A, Denora N, Iacobazzi RM, et al. Synthesis, characterization, and in vitro cytotoxicity of a Kiteplatin-Ibuprofen Pt(IV) prodrug. Inorg Chim Acta. 2018;472:221-228. doi:10.1016/j.ica.2017.07.019

36. Petruzzella E, Sirota R, Solazzo I, Gandin V, Gibson D. Triple action $\mathrm{Pt}$ (iv) derivatives of cisplatin: a new class of potent anticancer agents that overcome resistance. Chem Sci. 2018;9(18):4299-4307. doi: $10.1039 / \mathrm{c} 8 \mathrm{sc} 00428 \mathrm{e}$

37. Tolan DA, Abdel-Monem YK, El-Nagar MA. Anti-tumor platinum (IV) complexes bearing the anti-inflammatory drug naproxen in the axial position. Appl Organometal Chem. 2019;33(3):e4763. doi:10.1002/ aoc. 4763

38. Intini FP, Zajac J, Novohradsky V, et al. Novel antitumor platinum(II) conjugates containing the nonsteroidal anti-inflammatory agent diclofenac: synthesis and dual mechanisms of antiproliferative effects. Inorg Chem. 2017;56(3):1483-1497. doi:10.1021/acs. inorgchem.6b02553

39. Chen Y, Wang Q, Li Z, et al. Naproxen platinum(iv) hybrids inhibiting cycloxygenases and matrix metalloproteinases and causing DNA damage: synthesis and biological evaluation as antitumor agents in vitro and in vivo. Dalton Trans. 2020;49(16):5192-5204. doi:10.1039/D0DT00424C 
40. Jin S, Muhammad N, Sun Y, et al. Multispecific platinum(IV) complex deters breast cancer via interposing inflammation and immunosuppression as an inhibitor of COX-2 and PD-L1. Angew Chem Int Ed Engl. 2020;59(51):23313-23321. doi:10.1002/anie.202011273

41. Wang Q, Huang Z, Ma J, et al. Design, synthesis and biological evaluation of a novel series of glycosylated platinum(iv) complexes as antitumor agents. Dalton Trans. 2016;45(25):10366-10374. doi:10.1039/C6DT01562J

42. Wang QP, Tan XX, Liu ZF, et al. Design and synthesis of a new series of low toxic naphthalimide platinum(IV) antitumor complexes with dual DNA damage mechanism. Eur $J$ Pharm Sci. 2018;124:127-136. doi:10.1016/j.ejps.2018.08.032

43. Liu Z, Li Z, Du T, et al. Design, synthesis and biological evaluation of dihydro-2-quinolone platinum(IV) hybrids as antitumor agents displaying mitochondria injury and DNA damage mechanism. Dalton Trans. 2021;50:362-375. doi:10.1039/D0DT03194A

44. Wang QP, Li GS, Liu ZF, et al. Naphthalimide platinum(IV) compounds as antitumor agents with dual DNA damage mechanism to overcome cisplatin resistance. Eur J Inorg Chem. 2018;40 (40):4442-4451. doi:10.1002/ejic.201800799

45. Wang Q, Chen Y, Li G, et al. A potent aminonaphthalimide platinum(IV) complex with effective antitumor activities in vitro and in vivo displaying dual DNA damage effects on tumor cells. Bioorg Med Chem Lett. 2019;29(20):126670. doi:10.1016/j.bmcl.2019.126670

46. Sameer AS. Colorectal cancer: molecular mutations and polymorphisms. Front Oncol. 2013;3:114. doi:10.3389/fonc.2013.00114

47. Wu Y, Hu X, Song L, Zhu J, Yu R. The inhibitory effect of a novel polypeptide fraction from arca subcrenata on cancer-related inflammation in human cervical cancer HeLa cells. Sci World J. 2014;2014:768938. doi:10.1155/2014/768938

48. Xiao K, Li Y, Luo J, et al. The effect of surface charge on in vivo biodistribution of PEG-oligocholic acid based micellar nanoparticles. Biomaterials. 2011;32(13):3435-3446. doi:10.1016/j.biomaterials.20 11.01 .021

49. Sun J, Jiang L, Lin Y, et al. Enhanced anticancer efficacy of paclitaxel through multistage tumor-targeting liposomes modified with RGD and KLA peptides. Int J Nanomed. 2017;12:1517-1537. doi:10. 2147/IJN.S122859
50. de Oliveira GA, Cheng RYS, Ridnour LA, et al. Inducible nitric oxide synthase in the carcinogenesis of gastrointestinal cancers. Antioxid Redox Signal. 2017;26(18):1059-1077. doi:10.1089/ars.2016.6850

51. Hu Y, Xiang J, Su L, Tang X. The regulation of nitric oxide in tumor progression and therapy. $J$ Int Med Res. 2020;48(2):30006 0520905985. doi:10.1177/0300060520905985

52. Özenver N, Efferth T. Small molecule inhibitors and stimulators of inducible nitric oxide synthase in cancer cells from natural origin (phytochemicals, marine compounds, antibiotics). Biochem Pharmacol. 2020;176:113792. doi:10.1016/j.bcp.2020.113792

53. Moncada S, Higgs A. The L-arginine-nitric oxide pathway. $N$ Engl J Med. 1993;329:2002-2012. doi:10.1056/NEJM199312303292706

54. Vahora H, Khan MA, Alalami U, Hussain A. The potential role of nitric oxide in halting cancer progression through chemoprevention. $J$ Cancer Prev. 2016;21(1):1-12. doi:10.15430/JCP.2016.21.1.1

55. Vannini F, Kashfi K, Nath N. The dual role of iNOS in cancer. Redox Biol. 2015;6:334-343. doi:10.1016/j.redox.2015.08.009

56. Zhang N, Liu C, Jin L, et al. Ketogenic diet elicits antitumor properties through inducing oxidative stress, inhibiting MMP-9 expression, and rebalancing M1/M2 tumor-associated macrophage phenotype in a mouse model of colon cancer. $J$ Agric Food Chem. 2020;68:11182-11196. doi:10.1021/acs.jafc.0c04041

57. Roy R, Yang J, Moses MA. Matrix metalloproteinases as novel biomarkers and potential therapeutic targets in human cancer. J Clin Oncol. 2009;27(31):5287-5297. doi:10.1200/JCO.2009.23.5556

58. Gialeli C, Theocharis AD, Karamanos NK. Roles of matrix metalloproteinases in cancer progression and their pharmacological targeting. FEBS J. 2011;278(1):16-27. doi:10.1111/j.1742-4658.20 10.07919.x

59. Yempala T, Babu T, Karmakar S, et al. Expanding the arsenal of $\mathrm{Pt}^{\mathrm{IV}}$ anticancer agents: multi-action $\mathrm{Pt}^{\mathrm{IV}}$ anticancer agents with bioactive ligands possessing a hydroxy functional group. Angew Chem Int Ed Engl. 2019;58(50):18218-18223. doi:10.1002/anie.201910014

60. Li Z, Chen Y, Liu Z, et al. Synthesis and biological evaluation of new mono naphthalimide platinum(IV) derivatives as antitumor agents with dual DNA damage mechanism. Monatsh Chem. 2020;151 (3):353-367. doi:10.1007/s00706-020-02561-1
International Journal of Nanomedicine

\section{Publish your work in this journal}

The International Journal of Nanomedicine is an international, peerreviewed journal focusing on the application of nanotechnology in diagnostics, therapeutics, and drug delivery systems throughout the biomedical field. This journal is indexed on PubMed Central, MedLine, CAS, SciSearch ${ }^{\circledR}$, Current Contents ${ }^{\circledR} /$ Clinical Medicine,
Journal Citation Reports/Science Edition, EMBase, Scopus and the Elsevier Bibliographic databases. The manuscript management system is completely online and includes a very quick and fair peer-review system, which is all easy to use. Visit http://www.dovepress.com/ testimonials.php to read real quotes from published authors. 